\title{
Recent weakening in the winter ENSO teleconnection over the North Atlantic-European region
}

\author{
Sara Ivasić ${ }^{1}$ (1) - Ivana Herceg-Bulić ${ }^{1}$ Martin P. King ${ }^{2}$
}

Received: 28 October 2020 / Accepted: 22 April 2021 / Published online: 4 May 2021

(c) The Author(s) 2021

\begin{abstract}
New observational evidence for variability of the atmospheric response to wintertime El Niño-Southern Oscillation (ENSO) is found. Using different approaches and datasets, a weakening in the recent ENSO teleconnection over the North AtlanticEuropean (NAE) region is demonstrated. Changes in both pattern and strength of the teleconnection indicate a turning point in the 1970s with a shift from a response resembling the North Atlantic Oscillation (NAO) to an anomaly pattern orthogonal to NAO with very weak or statistically non-significant values; and to nearly non-existent teleconnection in the most recent decades. Results shows the importance of the background sea surface temperature (SST) state and sea-ice climatology having opposite effects in modulating the ENSO-NAE teleconnection. As indicated with targeted simulations, the recent change in the SST climatology in the Atlantic and Arctic has contributed to the weakening of the ENSO effect. The findings of this study can have implications on our understanding of modulations of ENSO teleconnections and ENSO as a source of predictability in the NAE sector.
\end{abstract}

Keywords ENSO teleconnections $\cdot$ Modulation of teleconnections $\cdot$ North Atlantic-European climate $\cdot$ NAO

\section{Introduction}

El Niño-Southern Oscillation (ENSO) is a phenomenon driven by the atmosphere-ocean interaction and a strong driver of climate variability all over the world (Lin and Qian 2019). ENSO has been attracting scientific attention because of its complexity of physics (Barnett et al. 1991; Wang and Picaut 2004), world-wide climate impacts (Brönnimann 2007; Ropelewski and Halpert 1989), predictability (Ren et al. 2019), and the possible implications for seasonal forecasts (Smith and O'Brien 2001; Scaife et al. 2014; van Oldenborgh et al. 2005). Detection of the ENSO-related signal in some parts of the midlatitudes is not straightforward because of the 'noisy' internal variability of the extratropical atmosphere (Colfescu and Schneider 2017) and other stronger influences which can modulate or even mask the ENSO signature. It is well known that the weather and climate of

Sara Ivasić

sivasic@gfz.hr

1 Department of Geophysics, Faculty of Science, University of Zagreb, Zagreb, Croatia

2 Geophysical Institute, University of Bergen, Bergen, Norway the North Atlantic-European area (NAE) are affected dominantly by the North Atlantic Oscillation (NAO) (Hurrell et al. 2003). Although this phenomenon exists throughout the year, it is most prominent during winter. Due to interest in its strong impact, $\mathrm{NAO}$ has been extensively investigated and abundant evidence of its influence, manifestation and variability on different timescales has been reported. The impact of NAO that extends over a great area from eastern North America to western and central Europe is reflected in temperature, precipitation, and intensity and location of the North Atlantic storm tracks (Wettstein and Wallace 2010; Woollings et al. 2015). According to the existing evidence, NAO may be considered a result of the internal atmospheric dynamical processes through the interaction between eddies and the mean flow (Lau 1981; Limpasuvan and Hartmann 1999; Vallis et al. 2004). Therefore, NAO is an internal mode of climate variability with weak predictable signal beyond the weather timescales. However, recent studies propose possible predictability of NAO through driving physical climate processes that are themselves predictable to some extent, such as tropical precipitation and the North Atlantic sub-tropical gyre (Domeisen et al. 2018; Scaife et al. 2014, 2017). 
Variability of the extratropical atmosphere can be affected by ENSO through the so-called teleconnections. While the ENSO impact is quite clear for certain regions, like Australia and Pacific-North America (PNA) (Power et al. 1999; Ropelewski and Halpert 1986), its influence on some other regions, such as NAE, is challenging to establish. There is considerable uncertainty on the amplitude and pattern of the atmospheric response to ENSO over NAE due to internal variability of the atmosphere (Deser et al. 2017). However, other studies indicate that the timing, spatial pattern and strength of the ENSO impacts can be considerable over the NAE region. The response is seasonally dependent, and there is a substantial difference even between the teleconnection patterns for early (November-December) and late (January-March) winter (Ayarzagüena et al. 2018; JiménezEsteve and Domeisen 2018; King et al. 2018; Molteni et al. 2015, 2020). While the wave-train originating in tropical Pacific is predominantly responsible for the ENSO influence on NAE region in late winter, interactions between tropical Pacific, Indian Ocean and Atlantic basins are important for establishing the early winter ENSO teleconnection to the NAE region (Abid et al. 2020b; Ayarzagüena et al. 2018). Various atmospheric processes that can impact and modulate the signature of ENSO in NAE area exist. An important contributor to the observed variety of the ENSO teleconnections is the diversity, in strength and pattern, of the ENSO events that can produce diverse responses (Calvo et al. 2017; Ineson and Scaife 2009; Iza and Calvo 2015; Larkin 2005; Li and Lau 2012; Toniazzo and Scaife 2006; Zhang et al. 2019).

Physical mechanism through which ENSO forces climate anomalies in the more distant parts of the world includes tropospheric propagation of the atmospheric Rossby waves (Horel and Wallace 1981; Hoskins and Karoly 1981; Kingtse and Livezey 1986). Alongside the tropospheric pathway, existing evidence shows that the tropical Pacific-NAE teleconnection is also established through the stratosphere. Vertically propagating waves associated with ENSO may perturb the polar stratosphere, which in turn affects the surface below (Bell et al. 2009; Calvo et al. 2017; Domeisen et al. 2019; Iza and Calvo 2015). In addition to the wintertime signal, the stratosphere may also support a prolonged ENSO impact from winter to spring by persistence of the winter ENSO signal (Herceg-Bulić et al. 2017).

Despite some disagreements between the previous results, most authors report a detectable ENSO-related signal in the European climate anomalies (Bartholy and Pongrácz 2006; Halpert and Ropelewski 1992; Kiladis and Diaz 1989; Rodó et al. 1997; Van Loon and Madden 1981). The canonical wintertime El Niño events are associated with a southward shift of the Atlantic cyclone track, more frequent cyclonic weather types over the NAE region and increased precipitation in the Mediterranean (Brönnimann 2007). La Niña events are mainly associated with the signal having almost symmetric pattern to that of the El Niño, with the opposite sign of the anomalies.

Regarding the spatial pattern of the ENSO teleconnections with the NAE region, a number of authors show that during the late winter ENSO impact on the European region projects onto the NAO pattern, with the warm phase (El Niño) resembling the negative NAO, and the cold phase (La Niña) resembling the positive NAO (Bell et al. 2009; Brönnimann 2007; Domeisen et al. 2015; Mezzina et al. 2019). However, Mezzina et al. (2019) argued that these two phenomena produce similar sea level pressure patterns in the NAE area via different dynamical mechanisms, which is indicated by the upper-tropospheric fields. The observed diversity of La Niña events can also have a significant impact on the atmospheric NAO-like response in the NAE area (Zhang et al. 2015). This relationship between ENSO and NAO shows non-stationarity on decadal timescales (Rodríguez-Fonseca et al. 2016).

We have described but a small part of the substantial progress that has been achieved in understanding the ENSO impact on NAE climate, but there are still many unsettled questions related to the strength, pattern, stationarity, and the underpinning physical mechanisms of the ENSO-NAE teleconnection (Bulić and Kucharski 2012; Hardiman et al. 2019; Lorenzo et al. 2011; Moron and Ward 1998; van Oldenborgh et al. 2000). In this study we look into the possible variation of ENSO and NAO co-occurrence to test the theory that the total ENSO influence on the NAE area projects onto the NAO pattern in late winter. From the results, non-stationarity of the ENSO teleconnection in the NAE area is found in both observed and modelled data. Finally, the potential cause for the weakening of this ENSO teleconnection is proposed, considering the decrease in the Arctic sea-ice cover and the background SST state.

\section{Materials and methods}

\subsection{Observational data}

To analyse mean-sea level pressure (MSLP) we have used the Hadley Centre (HadSLP2r) dataset (Allan and Ansell 2006). We also performed analysis for several other parameters (MSLP, zonal wind, geopotential height, temperature, surface ice concentration) taken from the NOAA 20th Century Reanalysis v3 (hereafter NOAA 20CR) (Slivinski et al. 2019). Niño 3.4 index from the HadISST dataset (Rayner et al. 2003) was used to define ENSO events, while the Hurrell PC-based NAO index was used to define NAO events. 


\subsection{Model}

We used the International Centre for Theoretical Physics (ICTP) atmospheric general circulation model (ICTP AGCM/SPEEDY) to investigate the effect of background SST on ENSO teleconnections. SPEEDY is an AGCM of intermediate complexity with a horizontal resolution of $3.75^{\circ}$ longitude $\times 3.75^{\circ}$ latitude with a spectral triangular truncation at wavenumber 30 (T30) and 8 vertical levels (Kucharski et al. 2006a, 2013; Molteni 2003). The prognostic vorticity-divergence equations are solved using a hydrostatic, $\sigma$-coordinate, spectral-transform method (Bourke 1974), with semi-implicit treatment of gravity waves. The model has parameterizations for various physical processes such as shortwave and longwave radiations, large-scale condensation, convection, and surface fluxes of momentum, heat, and moisture.

The model has been used in many studies, including those on the ENSO-Indian summer monsoon teleconnection (Kucharski et al. 2006b, 2007), tropical oceans teleconnection to Southwest Central Asia wet-season precipitation (Abid et al. 2020a), impact of the land-sea thermal contrast on the Northern Hemisphere climatic modes (Molteni et al. 2011), and the ENSO-related global teleconnections (Abid et al. 2020b; Bulić et al. 2012; Herceg Bulić and Branković 2007; Herceg-Bulić et al. 2017; Kucharski et al. 2006b, 2013). Under close examination in these studies, the model is able to re-produce well the general features of the various teleconnections pathways during different seasons and even differences between seasons (e.g. Abid et al. 2020b). It is now well-known that ENSO teleconnection to the extratropics involves tropospheric as well as stratospheric pathways (Domeisen et al. 2019). With SPEEDY's relatively coarse spatial resolutions and low top (at $\sigma=0.02$ ), it is reasonable to question its suitability for the present study. In the supporting information for Herceg-Bulić et al. (2017) the numerical treatments at the top two levels of SPEEDY are described; and variabilities of temperature and zonal winds at the model top are also examined [also see Fig. 11 in King et al. (2010)]. These variabilities are found to be similar to those in reanalysis and other models. King et al. (2010) also report the response in the model subject to top-levels temperature perturbation that imitate ozone reduction [see Fig. 14 and associated text in King et al. (2010)]. The resulting zonal-mean response that propagates to the troposphere through eddy forcing is found to be consistent with that reported by more in depth dynamical studies such as Simpson et al. (2009). It appears that the top two levels of SPEEDY can enable troposphere-lower-stratosphere interaction to some extent. The winds bias in the troposphere which in turn affects the accuracy of Rossby waveguiding is also an important factor for modelled teleconnection (e.g. Hoskins and Ambrizzi 1993; Li et al. 2020). We had not found that biases in SPEEDY affect simulation of the canonical ENSO teleconnections [see previous studies cited above, especially Fig. 4 in Kucharski et al. (2013)] so seriously that the model should not be used. One possible reason for the good model performance is that the tropospheric wind biases during DJF in the model is in fact very small (see http://users.ictp.it/ $\sim$ kucharsk/speedy8_clim.html). The previous studies and evaluations described above, coupled with our experience in using the model to research tropical-extratropical teleconnections give us some confidence in using SPEEDY for the present exploration.

We performed many experiments consisting of 210-year long simulations (the beginning 10 years are discarded). The model was forced with monthly-varying anomalous El Niño or La Niña SSTs that are repeating annually (Fig. 1b). The same anomalous ENSO SSTs are superimposed on different SST and sea-ice climatologies in the different experiments. Investigation of the modulation of the ENSO teleconnections by the background states due to changes in SST and seaice concentration (SIC) climatologies is based on different combinations of 'early' or 'late' SST and 'high' or 'low' SIC climatologies. Here, the 'early'/'high' climatologies are calculated from the 1979-1999 period, and 'late'/'low' climatologies from the 2005-2015 period. The difference of 'early' from 'late' SST climatologies used in the model experiments is shown in the Fig. 1a. In the Sect. 3.1, we

(a) 'Early' - 'late' SST, Jan/Feb, CI $=0.25 \mathrm{~K}$

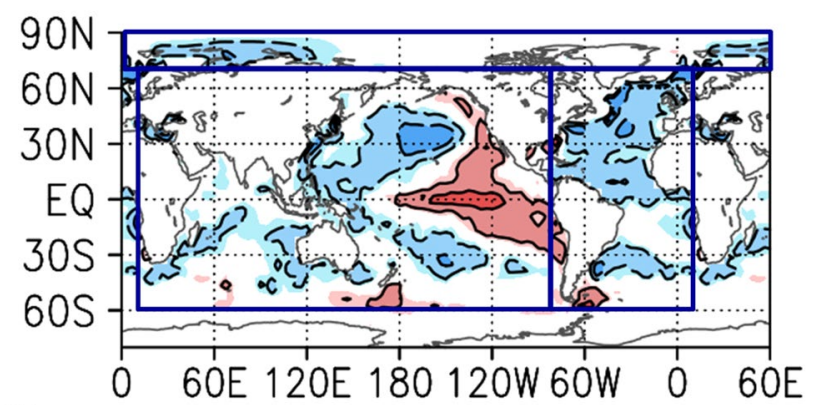

(b) El Nino SST, Jan $/ \mathrm{Feb}, \mathrm{Cl}=0.25 \mathrm{~K}$

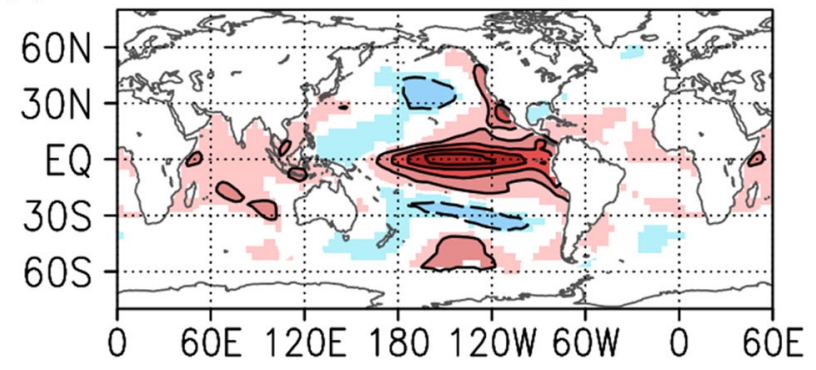

Fig. 1 a 'Early' (1979-1999) minus 'late' (2005-2015) SST climatologies used in the model experiments. b El Niño SST anomaly applied; La Niña is exact opposite of this. Both the climatology and anomalous SST applied in the model experiments are monthly varying but only Jan/Feb are shown here. Original data is from HadISST 
describe the climatological skin temperature difference over oceans and sea-ice for the experimental results presented.

The atmospheric response, in terms of anomalies of certain variables, due to ENSO is calculated by subtracting a control run (forced globally prescribed climatological SST and SIC with no ENSO) from another experiment with ENSO SST anomaly superimposed on the same SST and SIC climatologies. To isolate the modulating impact of the SST climatology in different ocean basins, we have also performed further 'low' sea-ice experiments with different combinations of 'early' and 'late' SST climatologies prescribed in three different ocean regions (Arctic, Indian and Pacific, and Atlantic oceans). These results are described in detail in the Sect. 3.1 of the paper.

\subsection{Classification of ENSO and NAO events}

ENSO years were categorized according to the strength of the winter (January, February, and March, hereafter JFM) Niño 3.4 index (HadISST), defined as SST anomalies averaged over $5^{\circ} \mathrm{S}-5^{\circ} \mathrm{N}$ and $120^{\circ}-170^{\circ} \mathrm{W}$. NAO years were classified based on the JFM NAO index, the first principal component (PC1) of JFM mean sea level pressure (MSLP) over the North Atlantic-European region $\left(20^{\circ}-80^{\circ} \mathrm{N}\right.$, $90^{\circ} \mathrm{W}-40^{\circ} \mathrm{E}$ ). There are three different categories in which the values of both of the standardized indices are sorted: negative $(I<-0.5 \sigma)$, neutral $(I \in[-0.5 \sigma, 0.5 \sigma])$ and positive $(I>0.5 \sigma)$.

\section{Results}

\subsection{Variation of ENSO and NAO cO-occurrence}

According to the scientific literature concerning the ENSONAE teleconnection in late winter, it is widely accepted that the ENSO impact on the NAE region projects onto a NAO-like pattern, with positive ENSO being associated with the negative NAO. In that case, one would expect the ENSO index (which measures the strength and phase of an ENSO event) to be correlated with the NAO index (which represents the spatial distribution and strength of a particular $\mathrm{NAO}$ event). In order to examine the relative occurrence of ENSO and NAO, probability distributions of NAO phases during three ENSO states are presented in Figs. 2 and 3. ENSO events are sorted according to the value of the HadISST Niño 3.4 index, where ENSOpos signifies the warm ENSO phase (El Niño), the cold ENSO phase (La Niña) is denoted as ENSOneg, while ENSO0 stands for neutral ENSO events. Following the same principle, the NAO events are sorted into positive, negative and neutral categories according to the value of the PC-based Hurrell NAO index.

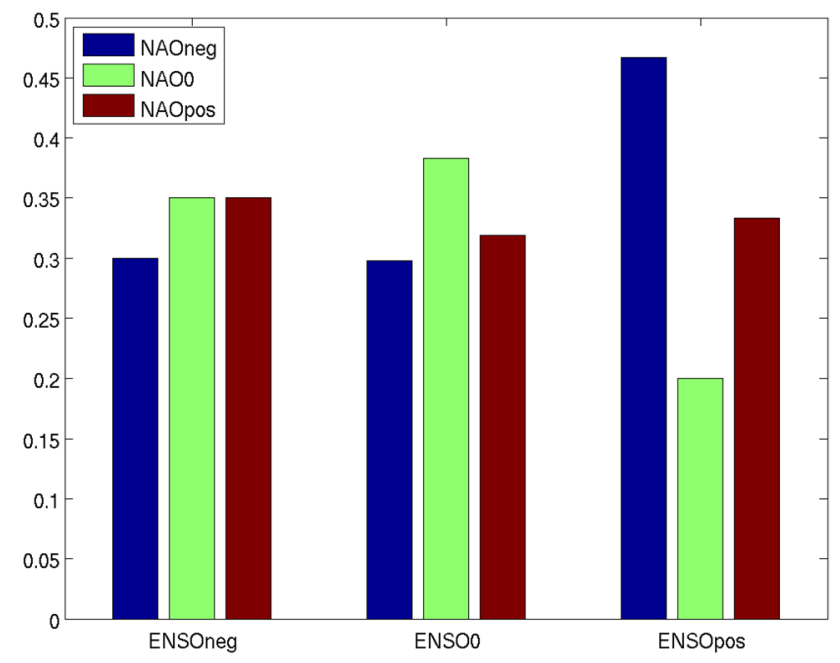

Fig. 2 Probability distribution of NAO phases during a particular ENSO phase for HadSLP data for the period 1899-2015. ENSO0 (neutral), ENSOneg (La Niña) and ENSOpos (El Niño) events are defined by the values of JFM HadISST Niño 3.4 index (ENSO0: $-0.5 \sigma \leq \mathrm{I} \leq 0.5 \sigma$, ENSOneg: $\mathrm{I}<-0.5 \sigma$, ENSOpos: $\mathrm{I}>0.5 \sigma)$. Analogous definition is made for NAO events and NAO index (JFM Hurrell PC-based NAO index)

Figure 2 shows how many times in the investigated period events connected to a certain ENSO phase (ENSOneg, ENSOpos and ENSO0) were accompanied by the negative, positive or neutral NAO. According to the HadSLP data, there are 40 ENSOneg events in total and 35\% of them are associated with the positive NAO, $30 \%$ with the negative phase of NAO and 35\% with its neutral phase. The distribution for 30 ENSOpos events is slightly different. Out of all recorded ENSOpos events, $47 \%$ are accompanied by negative NAO, $33 \%$ by positive and $20 \%$ by neutral NAO. At first glance, distributions presented in Fig. 2 confirm the previous findings that the warm ENSO phase (El Niño) is connected with the negative NAO (e.g. Bell et al. 2009; Brönnimann 2007; Domeisen et al. 2015), because a larger number of ENSOpos events co-occurs with the negative phase of NAO.

In order to examine if a similar distribution of ENSO and NAO events is maintained on shorter time scales, we plotted the probability distributions for successive 30 -year periods with an overlap of 20 years from 1899 to 2018 (Fig. 3). They reveal temporal non-stationarity of the ENSO-NAO relationship. In the first seven periods, warm ENSO is more frequently accompanied by negative NAO than by positive NAO. Particularly, the ENSOpos-NAOneg occurrences are predominant in the following sub-periods: 1909-1938, 1919-1948, 1929-1958, 1939-1968 and 1949-1978. However, in the sub-period 1969-1998 the situation has reversed and there are more cases when warm ENSO (ENSOpos) is accompanied by positive NAO (NAOpos) than those accompanied by negative NAO. The difference is even 
Fig. 3 Probability distribution of NAO phases during a particular ENSO phase for HadSLP data for a 1899-1928,

b 1909-1938, c 1919-1948,

d 1929-1958, e 1939-1968, f

1949-1978, g 1959-1988, h

1969-1998, i 1979-2008, and

j 1989-2018. ENSO0 (neu-

tral), ENSOneg (La Niña) and

ENSOpos (El Niño) events

are defined by the values of

JFM HadISST Niño 3.4 index

(ENSO0: $-0.5 \sigma \leq \mathrm{I} \leq 0.5 \sigma$,

ENSOneg: $\mathrm{I}<-0.5 \sigma$, ENSO-

pos: $\mathrm{I}>0.5 \sigma)$. Analogous defini-

tion is made for NAO events

and NAO index (JFM Hurrell

PC-based NAO index) (a) $1899-1928$

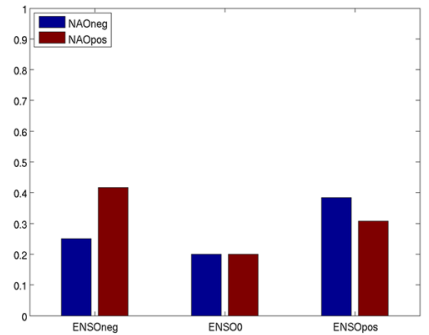

(c) $1919-1948$

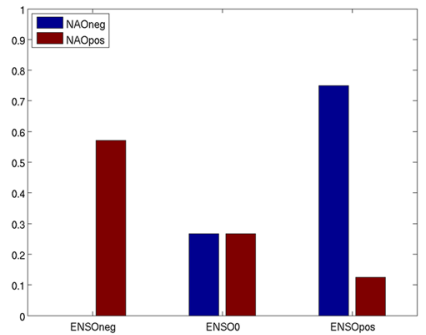

(e) $1939-1968$

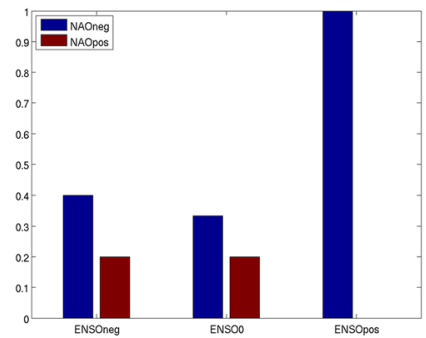

(g) 1959-1988

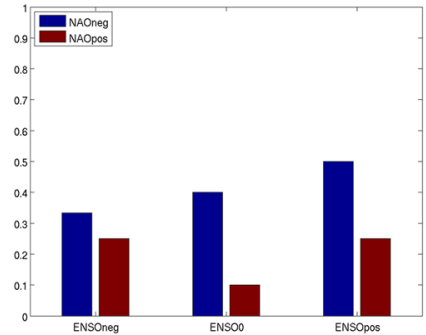

(i) $1979-2008$

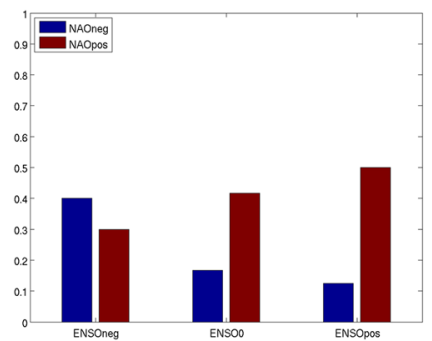

(b) $1909-1938$

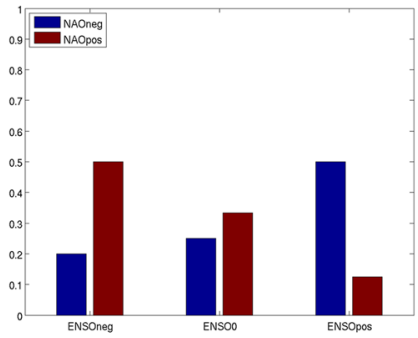

(d) $1929-1958$

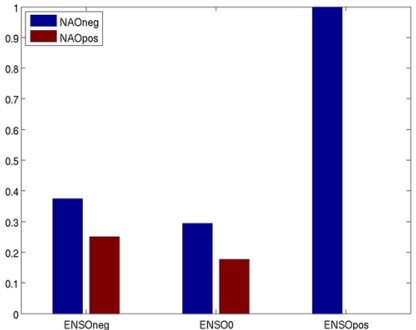

(f) $1949-1978$

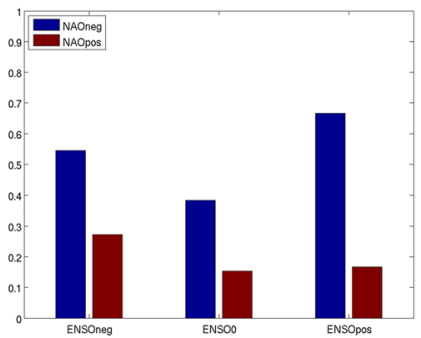

(h) $1969-1998$

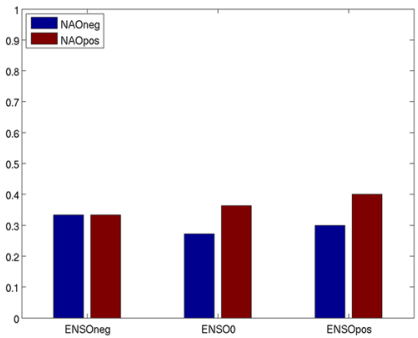

(j) $1989-2018$

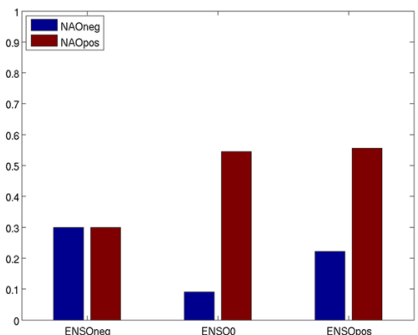

more pronounced in the last two sub-periods (1979-2008 and 1989-2018). This finding indicates the non-stationary behaviour of the ENSO-NAO occurrence with a change in the relative distribution of the ENSO and NAO indices in the 1970s. The probability distribution of different ENSO and NAO phases in overlapping 30-year long sub-periods made 
for ERA-20C reanalysis data (Poli et al. 2016) (not shown) confirms the previously described behaviour. When the decadal variability of the NAO index is removed by subtracting a 31-year moving average (not shown) from the standardized NAO index, the available period is shortened due to filtering. Nevertheless, the probability distribution using the filtered NAO index also points to the same observed change in the co-occurrence of ENSO and NAO phases.

In Fig. 3, ENSOneg (La Niña) events are more frequently accompanied by the positive phase of NAO in the first three 30-year periods (Fig. 3a-c). Starting from 1929 to 1958 period (Fig. 3d), ENSOneg-NAOneg combination becomes dominant in the following period, except for 1969-1998 (Fig. 3f) and 1989-2018 (Fig. 3j) when there is an equal number of events in both ENSOneg-NAOneg and ENSOneg-NAOpos categories.

The shift in ENSO-NAO occurrence is also supported by Fig. 4 showing a 31-year running correlation between the JFM HadISST Niño 3.4 and JFM Hurrell PC-based NAO index. The 31-year long correlation intervals are represented by the year in the centre of the interval, which is shown on the $\mathrm{x}$-axis (e.g. the correlation interval 1899-1929 is shown as 1914). The correlation coefficients with a negative sign indicate that the warm ENSO phase is mostly accompanied by negative NAO. The 31-year running correlation displays the temporal variability of the correlation between the two indices. At the beginning of the considered period, the correlation is not statistically significant. For the 31-year long periods starting around 1910, the correlation becomes statistically significant. The correlation, however, drops to nonsignificant values again for 31-year periods starting around 1940. To inspect the role of the observed decadal variability of the NAO index in the running correlation with the Niño
3.4 index, we repeated the calculation using a filtered NAO index (not shown). Running correlation with the NAO index after removing the decadal variability points to the same conclusion suggested by the results in Fig. 4: the non-stationarity of the ENSO-NAO correlation and the weakening to statistically non-significant values around 1970.

\subsection{Non-stationarity in ENSO teleconnection over the NAE region}

Motivated by the non-stationarity of the ENSO-NAO connection illustrated in Figs. 2, 3 and 4, we investigate the teleconnection spatially with regression maps. Based on the results shown in Figs. 3 and 4, we chose the 1929-1958 period as an example of the earlier conditions in the ENSONAE teleconnection, and the 1979-2008 period as an example of the ENSO-NAE teleconnection after the observed change. The regressions for the two periods (and their difference) are presented in Figs. 5, 6, 7 and 8 for sea level pressure, zonal wind and geopotential heights at $200 \mathrm{hPa}$ level.

Regression of HadSLP onto the Niño 3.4 index for the whole considered period (Fig. 5c) indicates that there is a weak ENSO-related signal over the western part of the Northern Atlantic. However, regression made for two shorter (30-year) periods shows that the response resembles the negative NAO pattern for 1929-1958 period (Fig. 5a). Area with negative regression coefficients stretches from the eastern coast of North America across the Atlantic towards Europe and is accompanied by area with positive regression coefficients to the north. However, in the more recent period, 1979-2008 (Fig. 5b), the regression shows a significant change. The area with negative regression coefficients is very weak and is reduced to the middle of the Atlantic,

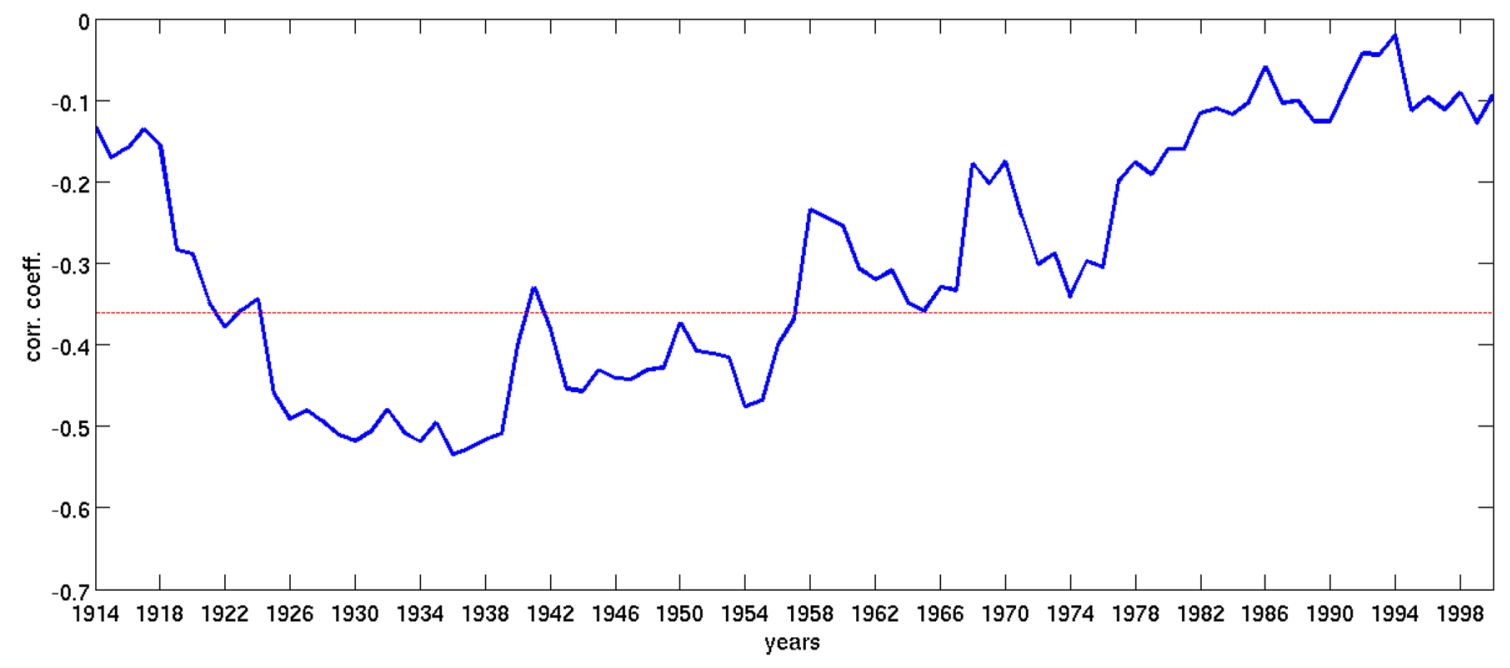

Fig. 4 31-year running correlation between the observed HadISST JFM Niño 3.4 and JFM Hurrell PC-based NAO index for 1899-2015. The $\mathrm{x}$-axis shows the centres of 31-year long correlation intervals.
Red line indicates statistically significant values in the 95\% confidence interval according to the two-tailed Student's $t$-test 
(a) regr JFM (Niño 3.4, HadSLP) 1929-1958

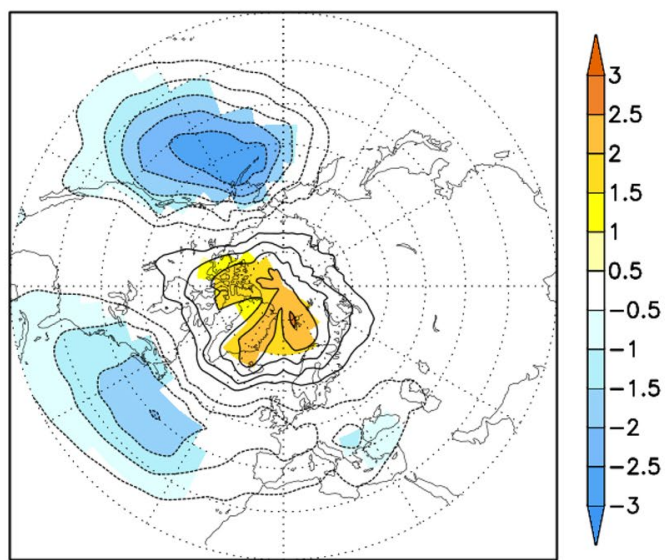

(c) regr JFM (Niño 3.4, HadSLP) 1899-2015

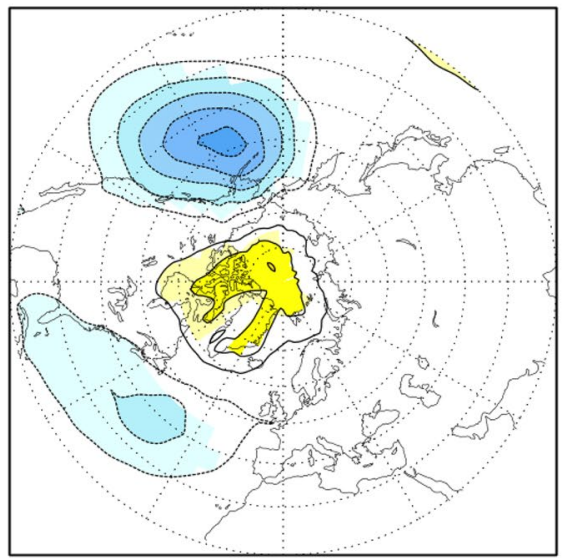

(b) regr JFM (Niño 3.4, HadSLP) 1979-2008

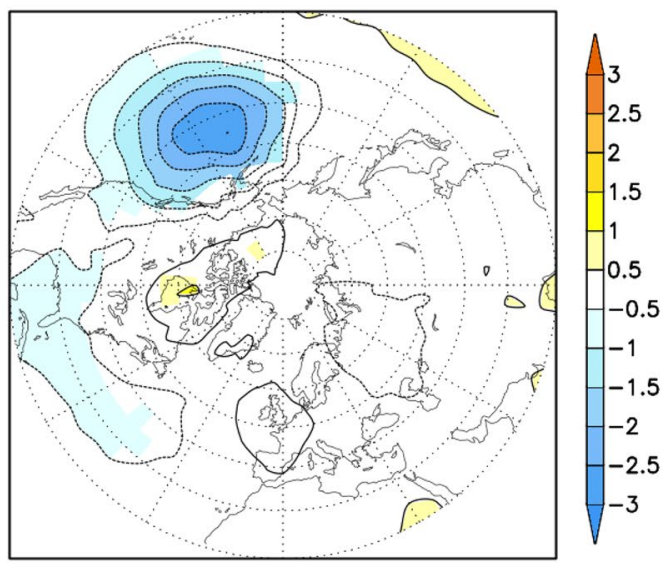

(d) diff regr JFM (Niño 3.4, HadSLP)

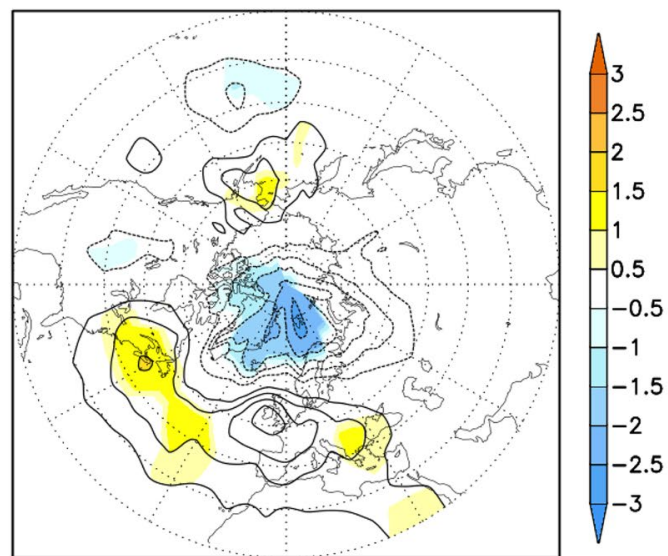

Fig. 5 Regression of JFM HadSLP onto JFM Niño 3.4 index (HadISST) $\left[\mathrm{hPa} /{ }^{\circ} \mathrm{C}\right]$ for a $1929-1958$, b 1979-2008, c 1899-2015, and d regression map in (b) minus regression map in (a). Statistically significant results $(\mathrm{p}<10 \%)$ are shaded

while the other parts of North Atlantic and Europe no longer show any statistically significant response. The change is evident when looking at the difference of the two regression maps (Fig. 5d). The difference between the later and the earlier considered 30-year period is large and statistically significant over the north-eastern part of North America, in the North Atlantic, and to the northwest of the Scandinavian Peninsula. Another dataset, NOAA 20CR, indicates the same features of the ENSO teleconnection over the NAE region: weakening of the atmospheric response over the Atlantic and Arctic in recent period (Fig. 6b). Again, NOAA 20CR dataset reveals a negative NAO-like response to ENSO for the earlier period (Fig. 6a). Similarly, as was obtained for the HadSLP data (Fig. 5c), when the whole period is considered, the regression is relatively weak over the NAE region (Fig. 6c). Figure 6d shows the difference between the regressions for the more recent (Fig. 6b) and earlier period (Fig. 6a) indicating remarkable changes in the response over the Atlantic and Arctic area. The difference is especially pronounced to the north-west of the Scandinavian Peninsula, and in the North Atlantic, west of the European continent.

To analyse the changes over time in more detail, we divided the total considered period into overlapping 30-year periods (Supp. Fig. S1), the same as the probability distributions presented in Fig. 3. Some of the earlier periods are associated with strong and statistically significant negative NAO-like response (i.e. 1909-1938 in Supp. Fig. S1c, 1919-1948 in Supp. Fig. S1d, 1929-1958 in Supp. Fig. S1e, and 1939-1968 in Supp. Fig. S1f). During these periods negative regression coefficients are found over the southern and eastern parts of Europe accompanied by positive coefficient over the Artic region. However, the response starts to weaken in the 1949-1978 period (Supp. Fig. S1g). It changes considerably in the later period (Supp. Fig. $\mathrm{S} 1 \mathrm{i}$ ), when the regression is non-significant over most of 
(a) regr JFM (Niño 3.4, NOAA 20CR SLP) 1929-1958

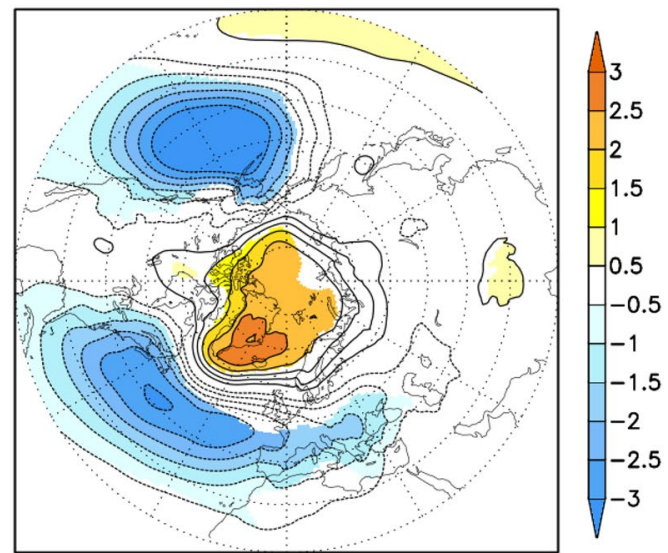

(c) regr JFM (Niño 3.4, NOAA 20CR SLP) 1899-2015

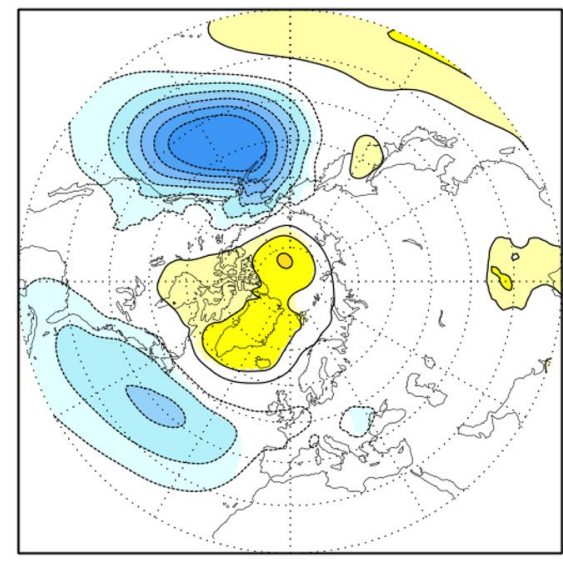

(b) regr JFM (Niño 3.4, NOAA 20CR SLP) 1979-2008

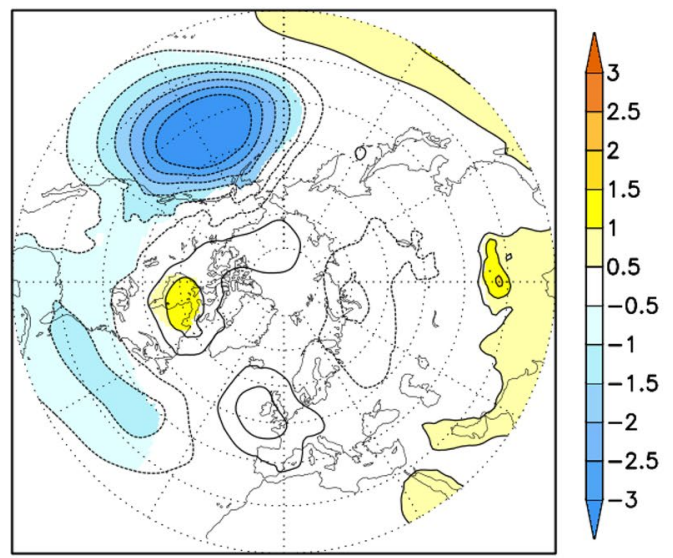

(d) diff regr JFM (Niño 3.4, NOAA 20CR SLP)

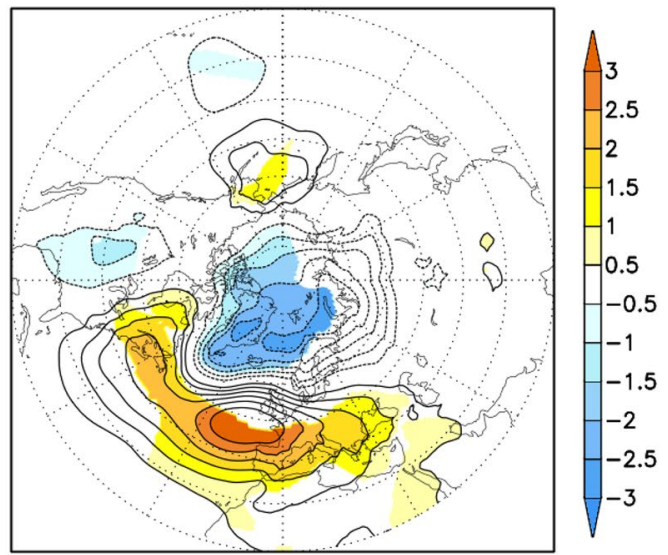

Fig. 6 Same as Fig. 5 except for JFM NOAA 20th Century Reanalysis v3 sea level pressure (SLP)

Europe. Weakening of the signal continues resulting in the non-significant response in last period (Supp. Fig. S1j). As already indicated by the Niño 3.4 and NAO index connection (Figs. 2, 3, 4), these results imply the existence of a change in the ENSO-NAE teleconnection in strength and spatial pattern of the atmospheric response.

Upper level fields confirm the temporal variability in the ENSO-NAE teleconnection found for sea level pressure (Figs. 5, 6). Regressions of geopotential height (GH200, GH500 and GH850) onto the Niño 3.4 index (Supp. Fig. S2) show a barotropic response. The regression maps for periods prior to and after the turning point indicate considerably different patterns. In fact, the responses presented in the left and right columns are orthogonal to each other in the Atlantic sector. Focusing on the $200 \mathrm{hPa}$ level (Fig. 7), the ENSO impact on the NAE region in the earlier period (Fig. 7a) is associated with positive regression coefficients over the northern Canada, which is accompanied by a zonally oriented belt of negative regression coefficients stretching from the eastern North America across the Atlantic towards the
European continent. In the later period, the negative regression coefficients are weaker (Fig. 7b) and the area does not reach the NAE region, unlike the case during the earlier period. The difference between the later and earlier period (Fig. 7d) shows significant values over northern Canada, and an area spanning from the eastern coast of North America towards Europe.

Consistent with the results for geopotential heights, the regression of zonal wind at $200 \mathrm{hPa}$ onto the Niño 3.4 index is modulated as well (Fig. 8). Zonal wind response to ENSO in the earlier period (Fig. 8a) contains positive regression coefficients on the southern part of the North Atlantic, linking North America and Europe, which are accompanied by negative regression coefficients in the northern, poleward side of the Atlantic (compare Fig. 11c). However, the response shows altered amplitude and spatial characteristics during the later period (Fig. 8b). In the later period zonal wind response does not reach the Eastern Atlantic and is disconnected from the European continent. This is also illustrated in the difference of the regression maps for the later 
(a) regr JFM (Niño 3.4, NOAA 20CR GH200) 1929-1958
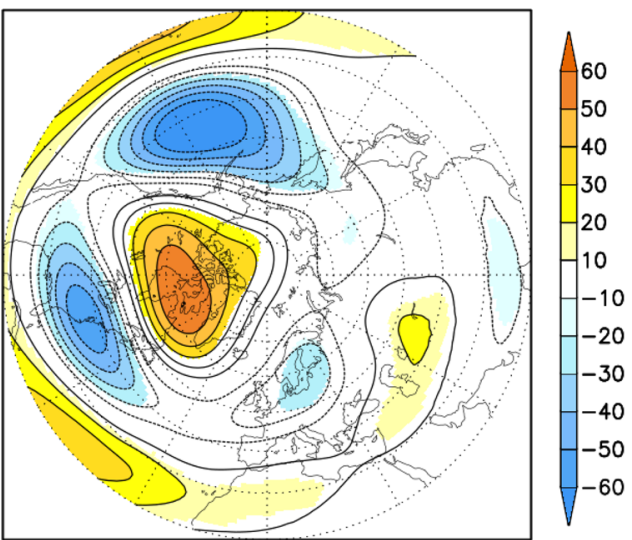

(c) regr JFM (Niño 3.4, NOAA 20CR GH200) 1899-2015

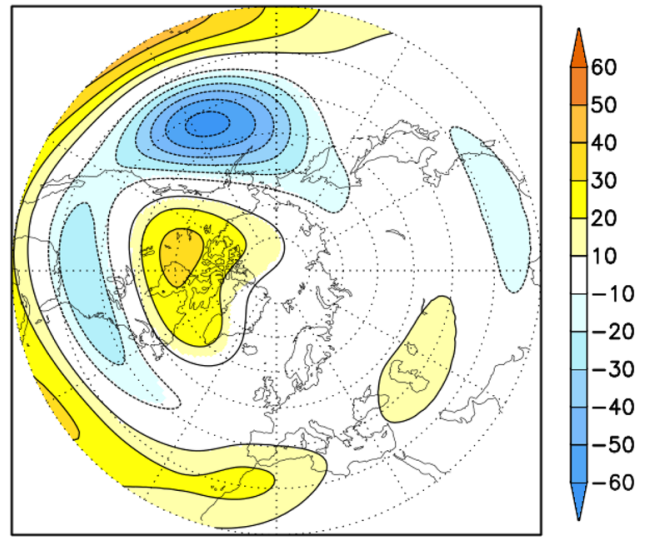

(b) regr JFM (Niño 3.4, NOAA 20CR GH200) 1979-2008

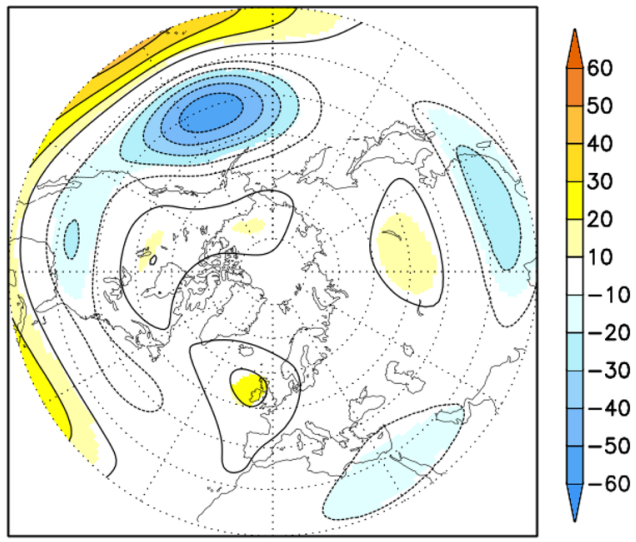

(d) diff regr JFM (Niño 3.4, NOAA 20CR GH200)

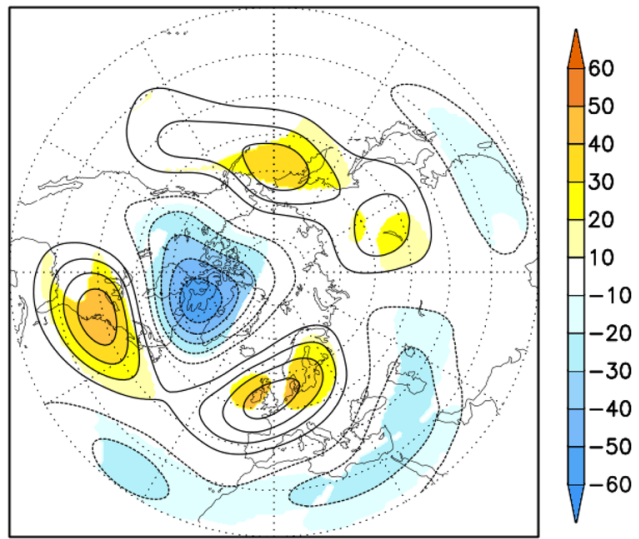

Fig. 7 Same as Fig. 5 except for JFM NOAA 20th Century Reanalysis v3 geopotential heights at $200 \mathrm{hPa}(\mathrm{GH} 200)\left[\mathrm{m} /{ }^{\circ} \mathrm{C}\right]$

and earlier period (Fig. 8d), which is statistically significant in the NAE region. This change in the response is present on different levels for zonal wind (not shown).

Changes in both patterns and strengths of geopotential height, mean sea level pressure and zonal wind regression maps indicate a shift in the ENSO impact on the NAE region which has occurred in the 1970s. Prior to 1970, the atmospheric response to ENSO over the NAE region had a form of two zonally oriented belts with stronger connection, in terms of the values of the regression coefficients (Fig. 8a). However, after 1970 the overall response over the NAE area is weakened (Fig. 8b) and anomalies do not reach the European continent (also compare Fig. 7a with b). It is found that during the most recent period not only the teleconnection pattern has changed, but also the mean sea level pressure response faded to non-significant values (Fig. S1j). It is shown that the results of the regression depend on the considered period and its length (e.g. Fig. 6a-c).

By examining the regression maps, we are focusing only on the linear part of the ENSO-NAE teleconnection. However, the signal related to ENSOneg (La Niña) phase over the NAE region is found to be nonlinear (Zhang et al. 2015). To distinguish the nonlinear signal, a separate analysis of the two ENSO phases, in form of ENSOpos (El Niño) and ENSOneg (La Niña) composites for HadSLP (Fig. 9) was made. Spatial distribution of the ENSO regression onto HadSLP (Fig. 5) and its change from earlier (Fig. 5a) to later 30-year period (Fig. 5b) is consistent with ENSOpos composites (Fig. 9a, c). The ENSOpos composite in the later 30-year period (Fig. 9c) changes sign of the spatial pattern over the NAE area, which agrees with the results shown in Fig. 3. Meanwhile, the HadSLP composites for ENSOneg events for the same two 30-year periods (Fig. 9b, d) have an overall weaker response over the NAE area and the spatial pattern is of the opposite sign. Despite the relatively small size of the presented composites, they imply that the observed change in the ENSO-NAE teleconnection is mainly due to the weakened ENSOpos-NAE connection. Also, results of the composite analysis revealed that the teleconnections associated with both of ENSO phases become weaker over the NAE region in the later 30-year period (Fig. 9c, d). 
(a) regr JFM (Niño 3.4, NOAA 20CR u200) 1929-1958
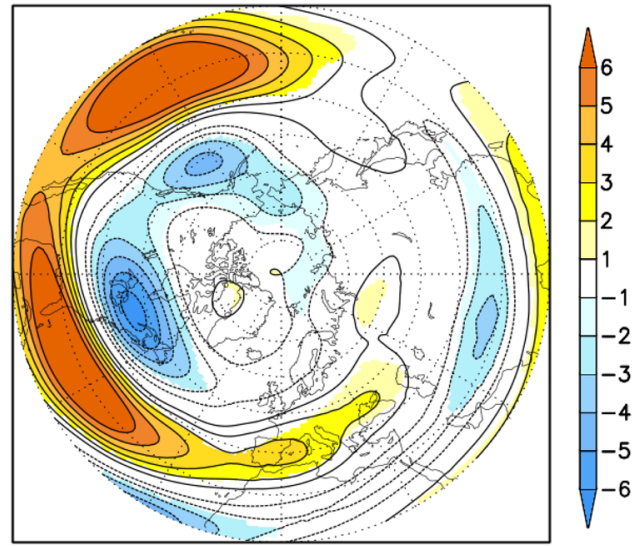

(c) regr JFM (Niño 3.4, NOAA 20CR u200) 1899-2015

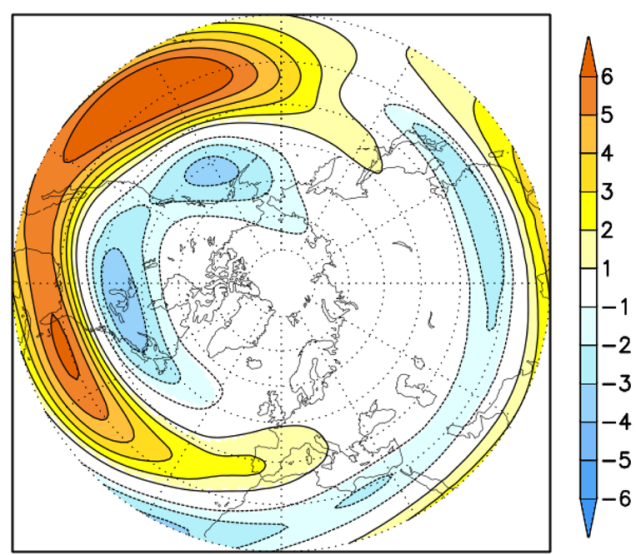

(b) regr JFM (Niño 3.4, NOAA 20CR u200) 1979-2008

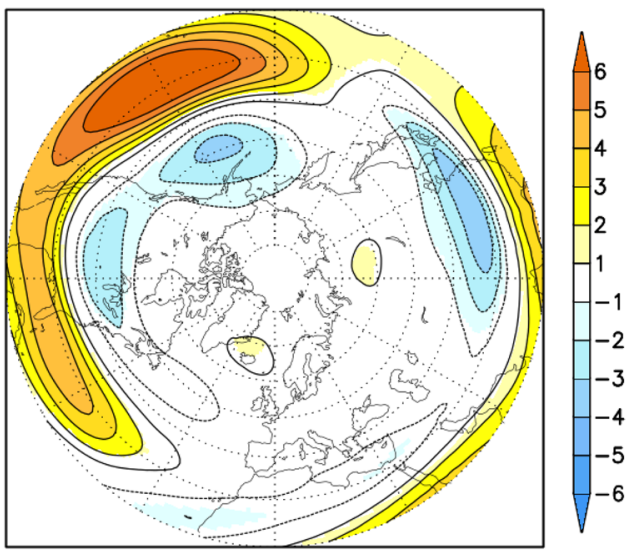

(d) diff regr JFM (Niño 3.4, NOAA 20CR u200)

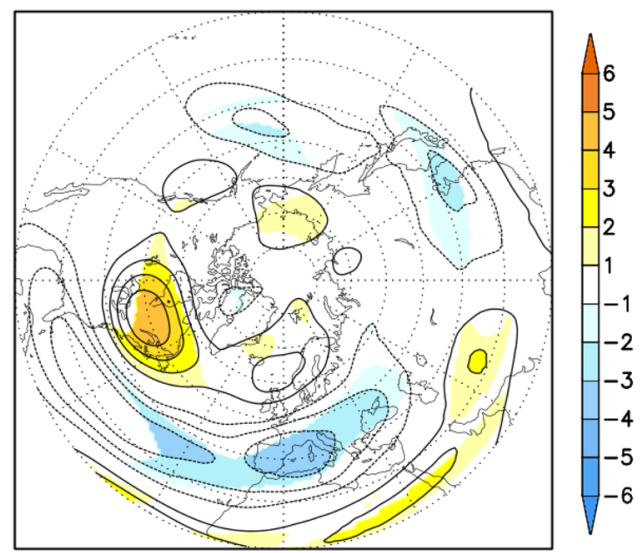

Fig. 8 Same as Fig. 5 except for JFM NOAA 20th Century Reanalysis v3 zonal wind at $200 \mathrm{hPa}$ (u200) $\left[\mathrm{m} \mathrm{s}^{-1}{ }^{\circ} \mathrm{C}^{-1}\right.$ ]

\subsection{Potential cause of weakened ENSO-NAE teleconnection}

Inspection of the regression maps from early to late 30 -year periods indicates a temporal modulation of the ENSO-NAE teleconnection. Therefore, we present results for other variables that may suggest the cause of the nonstationarity. First, we present temperature anomalies (based on the climatology for the 1899-2015 period) at $200 \mathrm{hPa}$ for two 30-year periods (Fig. 10). Comparing T200 anomalies in the earlier (Fig. 10a) and later period (Fig. 10b), and their difference (Fig. 10c), the warming of the subpolar northern Canada atmosphere is evident. In the earlier period, temperature anomalies over the polar region are weakly negative. However, in the later period, anomalies over the polar region strengthen and change their sign. The warming of the polar atmosphere modifies the meridional temperature gradient, which may induce changes in the speed and structure (e.g. waviness) of the jet stream (Cohen et al. 2014; Francis and Vavrus 2015; Cattiaux et al. 2016). Because the jet stream has an important role for teleconnections acting as waveguides (Branstator 2002), we present zonal wind change as well. Figure 11 shows zonal wind anomalies at $200 \mathrm{hPa}$ for two periods as above: earlier (1929-1958; Fig. 11a) and later (1979-2008; Fig. 11b). The difference between the later and earlier period, compared to the u200 climatology (Fig. 11c), reveals that in the later period the southern flank of the Atlantic jet has strengthened, indicating its equatorward shift. According to these results, the change in the strength and position of the jet coincides with the weakening of the ENSO-NAE teleconnection. Variability of the midlatitude atmospheric circulation has been widely investigated and many studies proposed Arctic warming and sea-ice loss as an important contributor (Gastineau and Frankignoul 2015; Screen et al. 2018; Warner et al. 2019). Furthermore, century-scale sea-ice extent analysis has shown that the sea-ice extent changed considerably in the Northern Hemisphere and has accelerated during the 
(a) JFM (ENSOpos, HadSLP) composite 1929-1958, $(\mathrm{n}=5)$

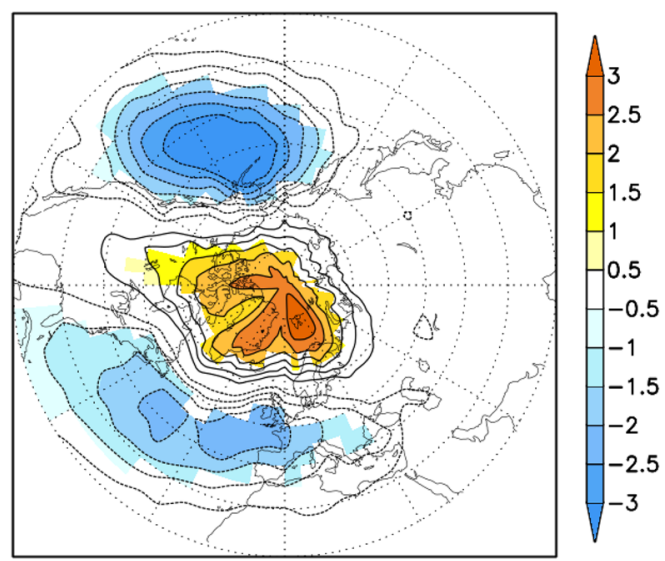

(c) JFM (ENSOpos, HadSLP) composite 1979-2008, $(\mathrm{n}=7)$

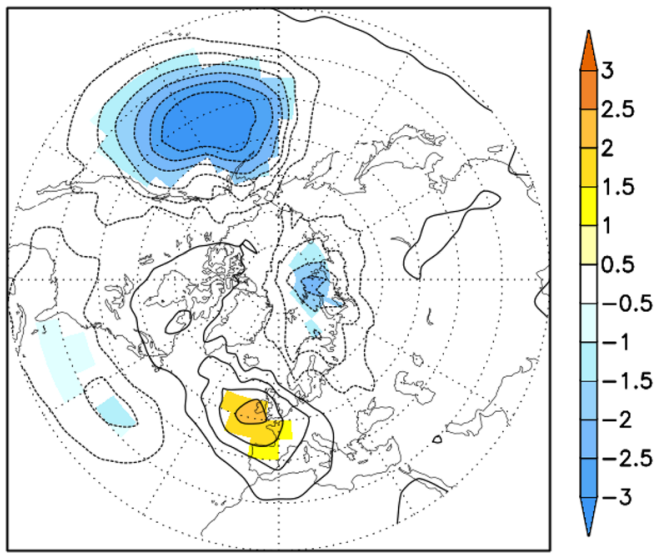

(e) JFM (ENSOpos, HadSLP) composite 1899-2015, $(\mathrm{n}=30)$

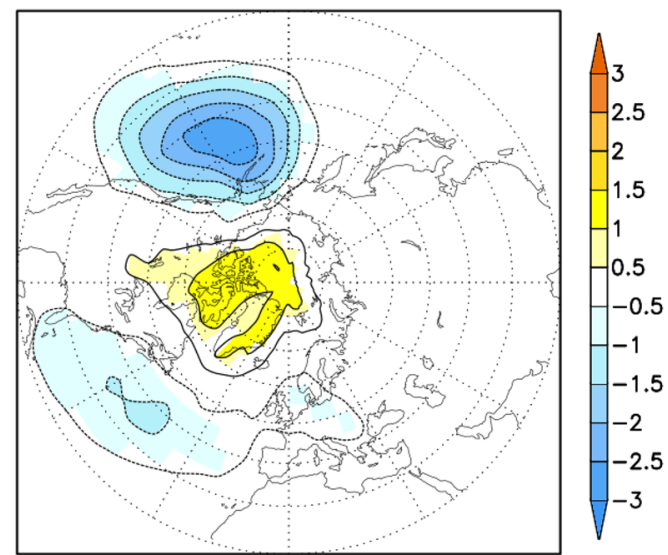

Fig. 9 Composites of JFM HadSLP [hPa] for ENSOpos (El Niño) and ENSOneg (La Niña) events for a, b 1929-1958, c, d 1979-2008, and e, f 1899-2015. ENSOpos events are defined as JFM HadISST Niño 3.4 index $>0.5 \sigma$, while ENSOneg are defined as JFM HadISST (b) JFM (ENSOneg, HadSLP) composite 1929-1958, $(\mathrm{n}=8)$

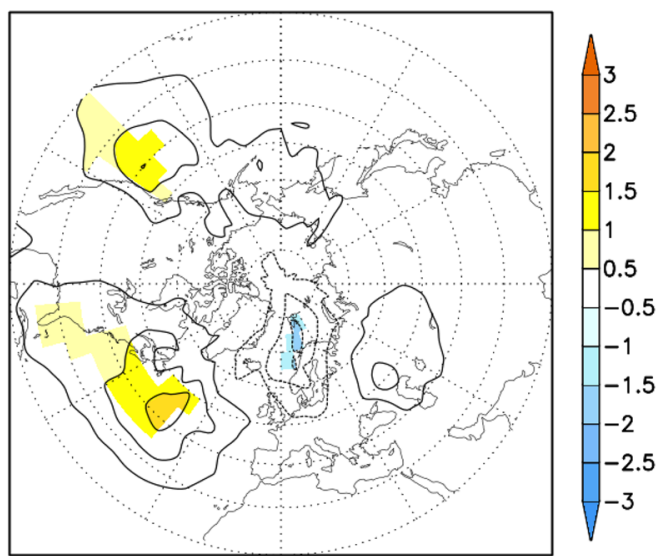

(d) JFM (ENSOneg, HadSLP) composite 1979-2008, $(\mathrm{n}=10)$

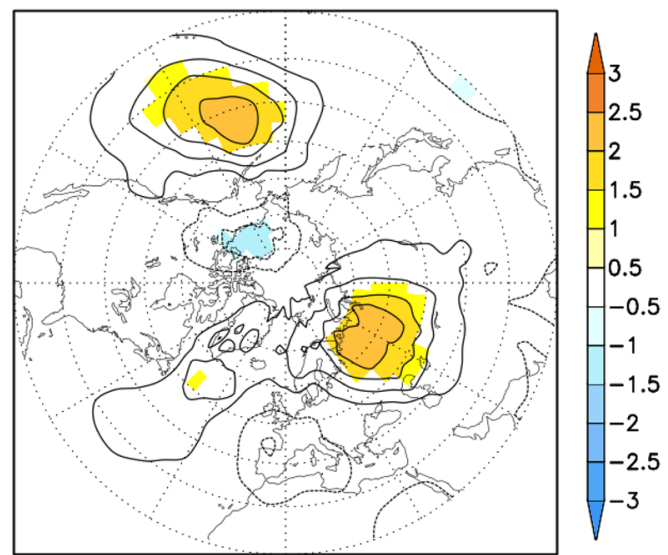

(f) JFM (ENSOneg, HadSLP) composite 1899-2015, $(\mathrm{n}=40)$

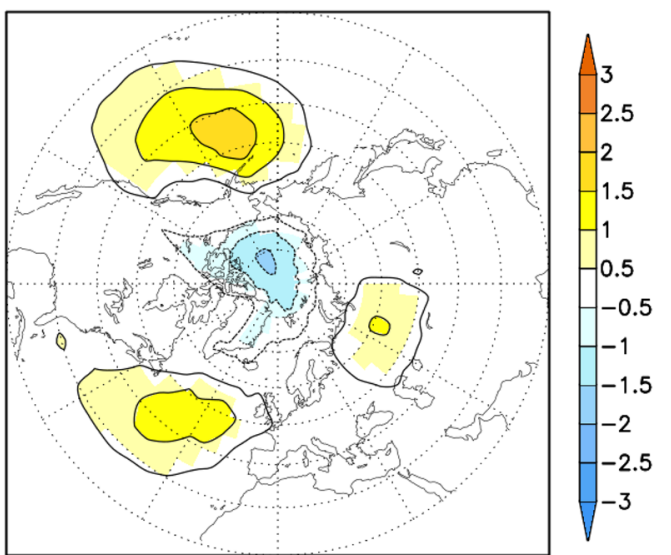

Niño 3.4 index $<-0.5 \sigma$. Number (n) of ENSOpos and ENSOneg events in each period is written in the parenthesis. Statistically significant results $(\mathrm{p}<10 \%)$ are shaded 
(a) NOAA 20CR T200 JFM anom 1929-1958
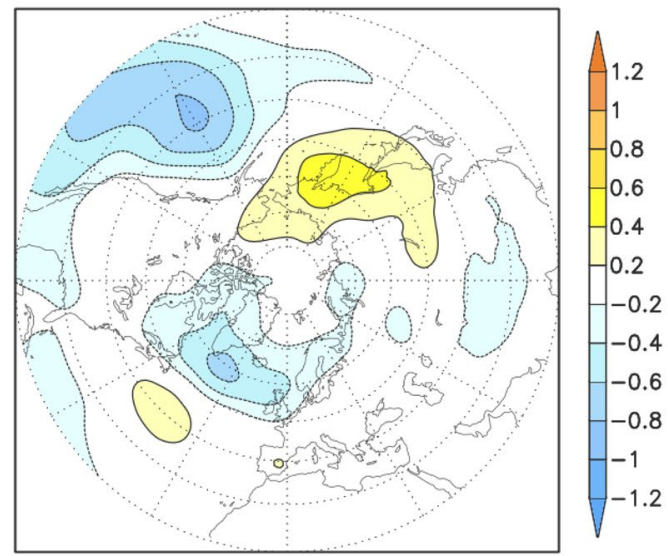

(c) diff JFM anom NOAA 20CR T200
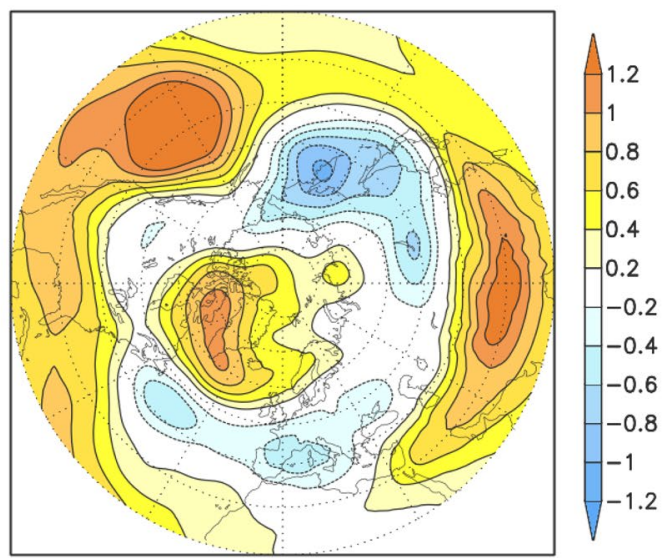

(b) NOAA 20CR T200 JFM anom 1979-2008

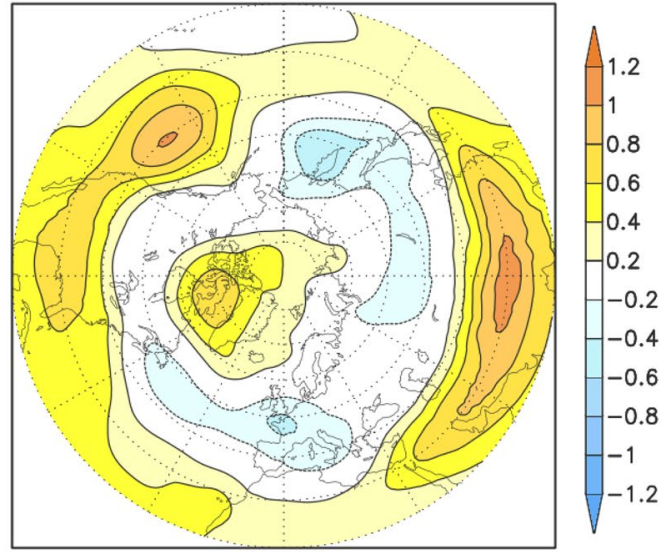

Fig. 10 NOAA 20th Century Reanalysis v3 averaged JFM temperature anomalies (using 1899-2015 climatology) at $200 \mathrm{hPa}(\mathrm{T} 200)\left[{ }^{\circ} \mathrm{C}\right]$ for a 1929-1958, b 1979-2008, and c anomalies in (b) minus anomalies in (a)

past several decades (Walsh and Chapman 2001). NOAA 20CR surface ice concentration anomalies averaged over the polar cap $\left(-180^{\circ}\right.$ to $\left.180^{\circ} \mathrm{E}, 70^{\circ}-90^{\circ} \mathrm{N}\right)$ for the period 1899-2015 (Fig. 12) show that the significant drop in the ice concentration coincides with the changes in the ENSO-NAO teleconnection over the NAE area. Moreover, both tropical and extratropical SSTs affect the atmosphere through remote forcing and local ocean-atmosphere interaction (Gastineau and Frankignoul 2015; Czaja et al. 2019). In the next section, we pose the following question using model experiments: what are the roles of Arctic seaice loss and change in SSTs in controlling the ENSO-NAE teleconnection?

\subsection{Modelling evidence}

In the previous sections, observational evidence of the weakening of the ENSO-NAE teleconnection is presented. In this section we report model results of investigating the modulation of ENSO-NAE teleconnections through background states that are controlled by SST and SIC.

Figure 13 shows the mean sea level pressure responses to El Niño in simulations with differently prescribed climatological values of SIC and SST. The experiment forced with El Niño SST under 'high' SIC and 'early' SST climatologies (Fig. 13a) simulated a canonical response to ENSO with a negative NAO-like pattern over the NAE region. However, the experiment forced with 'low' sea-ice and 'late' climatological SST (representing more recent conditions), turned out considerably different (Fig. 13b). Not only is the spatial pattern of the response changed (the pattern does not project onto the NAO pattern), the area of statistical significant values in the NAE sector has also shrunk. In particular, the anomaly over the Atlantic which links the action centres over the Gulf of Mexico and Europe is absent in the experiment with recent sea-ice and SST conditions. But what are the relative roles of sea-ice and SST changes in the weakening of the teleconnection over NAE? The ENSO forcing on 
(a) NOAA 20CR u200 JFM anom 1929-1958

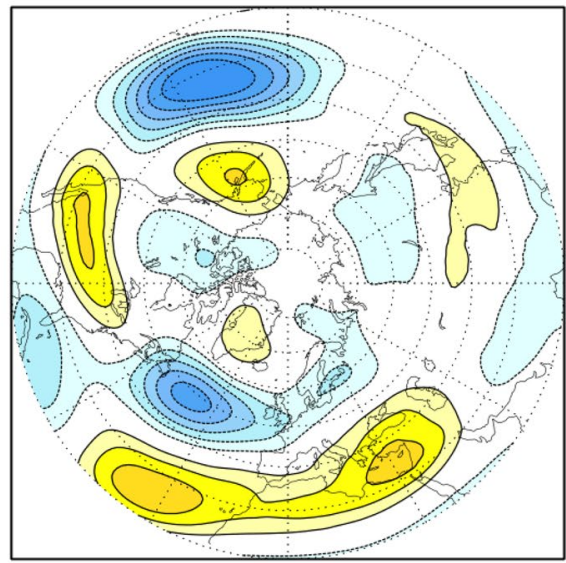

(c) diff JFM anom NOAA 20CR u200 (b) NOAA 20CR u200 JFM anom 1979-2008

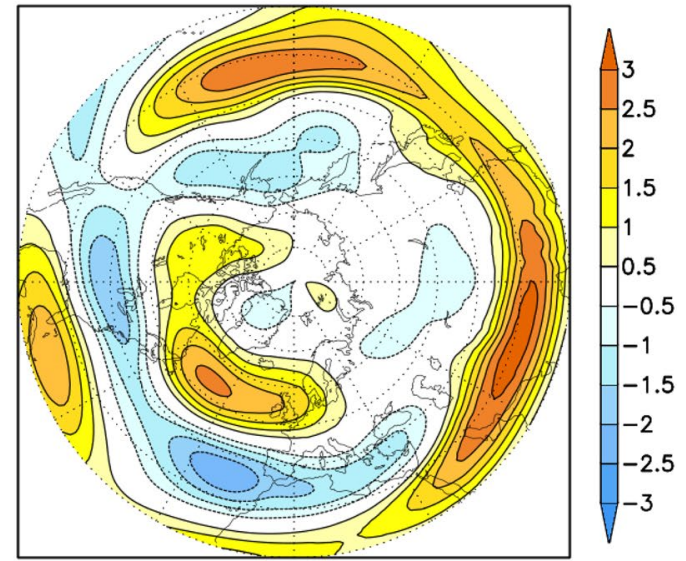

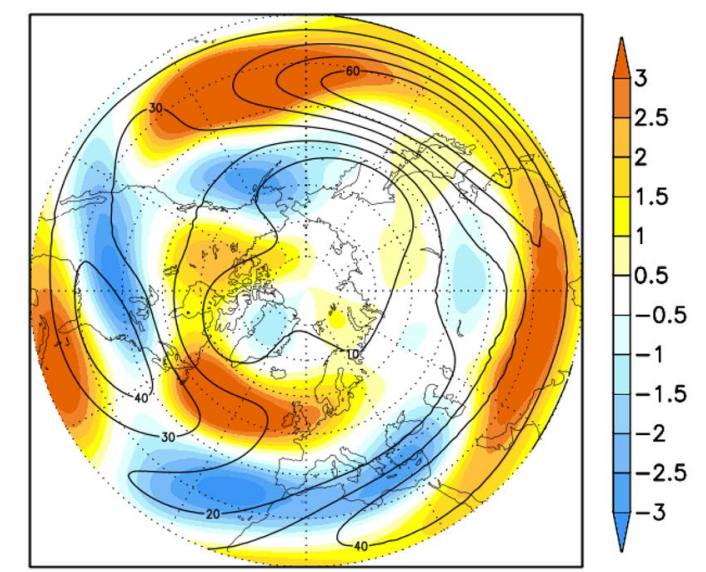

Fig. 11 NOAA 20th Century Reanalysis v3 averaged JFM zonal wind anomalies (using 1899-2015 climatology) at $200 \mathrm{hPa}$ (u200) $[\mathrm{m} / \mathrm{s}]$ for a 1929-1958, b 1979-2008, and c anomalies shown in (b)

background conditions with 'low' sea-ice but with a switch to 'early' SST climate in fact produces the strengthened response (compare Fig. 13b, d, and also Fig. 13f, h). On the other hand, the weakening of the signal is obtained for the experiment retaining the 'late' SST climatology but with a switch to 'high' sea-ice (Fig. 13c, g). This suggests that the 'late' SST climatology is responsible for the weakened ENSO teleconnection in the NAE. The GH200 response to ENSO (Fig. 13e-h) is consistent with the result for mean sea level pressure, manifesting similar dependence on the SST and sea-ice climatology throughout the atmosphere.

The above results highlight the role of the 'late' SST climatological state on weakening of the atmospheric response to ENSO, while the 'low' sea-ice climatology could have the opposite effects. The biggest difference in SSTs is found in the Pacific and northern Atlantic (Fig. 1a). The difference in what we call 'climatologies' can be due to the two stronger El Niños $(1982 / 83,1997 / 98)$ in the earlier period minus anomalies in (a) $[\mathrm{m} / \mathrm{s}]$ (shaded) with overlaid contours of JFM zonal wind (u200) climatology for period 1899-2015 (contour inter$\mathrm{val}=10 \mathrm{~m} / \mathrm{s})$

as well as other decadal variations between the two periods. To check, we repeated the calculation for Fig. 1a with these two El Niños excluded. Globally the pattern stays similar. In tropical Pacific, these two El Niños contribute to at most about $40 \%$ of the values in Fig. 1a. In the North Atlantic, the values largely do not change. The model experiments have been prescribed with identical El Niño anomaly on top of the different background states, so that whatever ENSO teleconnection differences resulted should be due to modulating factor(s), not to differences in El Niño strengths.

To explore the impact of the SST climatology in more detail, with the aim to identify which parts of the global oceans are necessary for the weakening, we repeated the 'low' sea-ice experiments with 'early' and 'late' SST climatologies prescribed in the different oceans. Three separate ocean basins are delineated for this purpose-Indian and Pacific Ocean, Arctic Ocean, and Atlantic Ocean, as shown by the boxes with blue borders in Fig. 1a. Also, shown in 


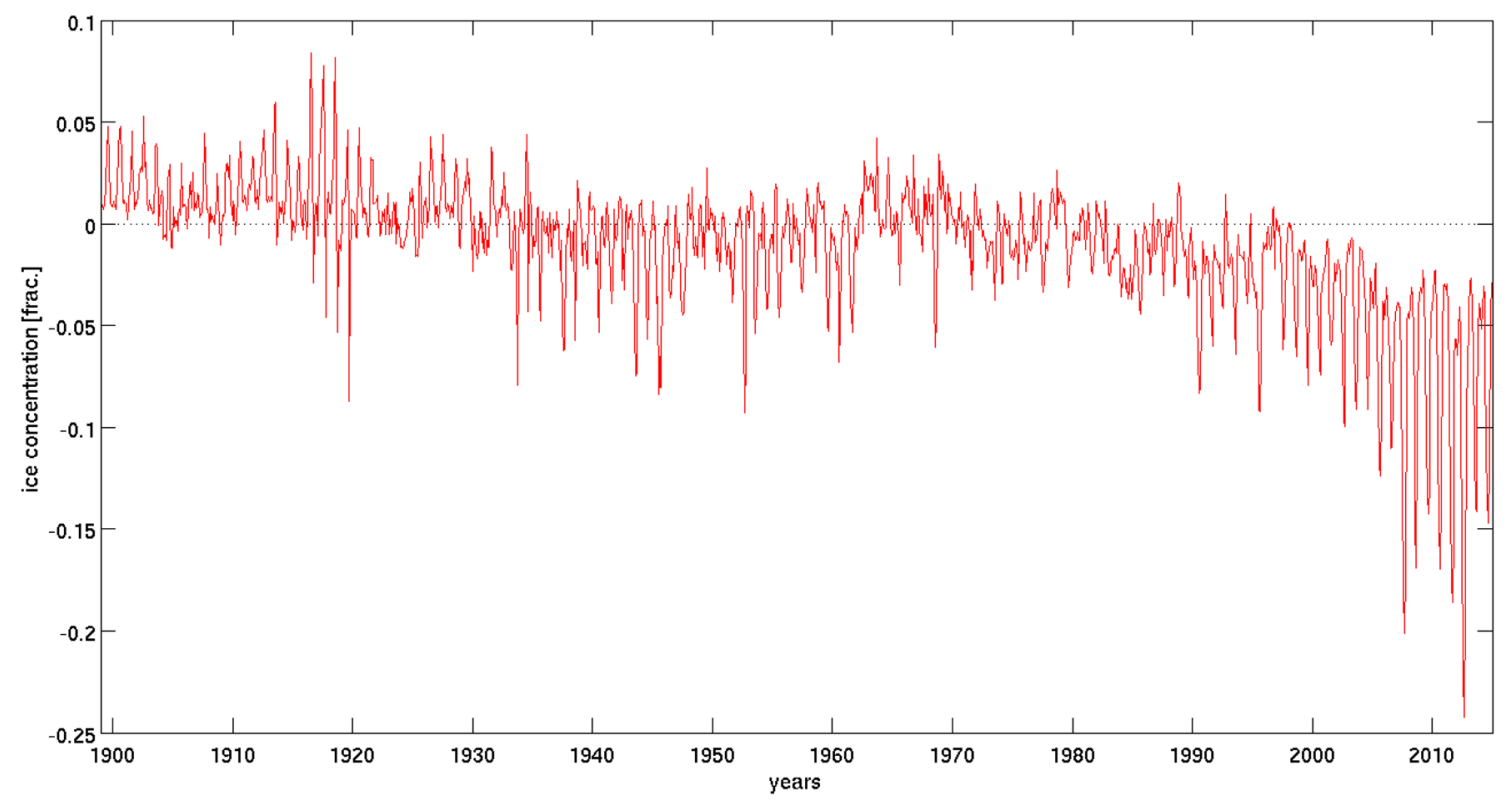

Fig. 12 NOAA 20th Century Reanalysis v3 surface ice concentration anomalies [frac.] averaged over the polar cap $\left(-180^{\circ}\right.$ to $180^{\circ} \mathrm{E}, 70^{\circ}$ to $90^{\circ}$ N) for the period 1899-2015

Fig. $1 \mathrm{~b}$ is the anomalous SST applied in all of the El Niño experiments. Since there are two climatological SSTs to choose from for each of the three ocean basins, eight unique combinations of 'early' or 'late' SST climatologies prescribed in these regions exist. All these eight experiments have been carried out. Results from two of them (all basins at 'early' or at 'late' SST) are already shown in Fig. 13. Figure 14 shows results from the other six, with the blue borders indicating the areas where the SST climatology is from the 'early' period, and the area outside of that is from the 'late' period. Atmospheric responses to El Niño under these conditions are then compared with the response the 'low' sea-ice conditions with globally prescribed 'late' SST climatology (Fig. 13b). The idea is to see which one(s) of these experiments revert from a weakened to a strengthened ENSO response that is similar to the 'low' sea-ice and 'early' SST everywhere which is shown in Fig. 13d. This approach allows examination of the sensitivity of the modelled atmospheric response to the background SST states.

With the experiment presented in Fig. 13b as a starting point, we consider the impact of reverting the SST climatology in the Indo-Pacific region to the 'early' SST climatology, while the 'late' SST climatology is kept elsewhere (Fig. 14a). The pattern is similar to that in Fig. 13b (i.e. anomalies form a monopole over the Eastern Atlantic detached from the anomalies covering Central America). In comparison with Fig. 13a, the NAE response in Fig. 14a is much weaker with statistically significant anomalies covering a very small area. The response is somewhat stronger when 'early' SST climatology is prescribed over the Arctic
Ocean (Fig. 14b), but it still retains the monopole form. Similar weak teleconnections in the NAE area are obtained for the experiment with 'early' SST climatology prescribed in the Atlantic (Fig. 14c). The results of Fig. 14a-c suggest that the change of SST climatology in these three ocean areas independently is not enough to substantially modify the result of Fig. 13b. The response still does not change significantly from Fig. 13b when we revert to 'early' SST climatology everywhere outside the Arctic Ocean (Fig. 14d) or outside the Atlantic Ocean (Fig. 14e). However, when 'early' SST climatology is prescribed in both the Arctic and Atlantic, the response changes simultaneously in the strength and pattern (Fig. 14f). The response then consists of non-significant positive northern centre and significant negative southern centre across the Atlantic (connected with anomalies covering Central America) and is a reminiscence of the responses under 'early' SST conditions (Fig. 13a, d). Experiments in Fig. 14 reveal that if the SST climatology in the Arctic and Atlantic is reverted to 'early' SST values, the teleconnection in the NAE region stays similar as that for low sea-ice and globally prescribed 'early' SST climatology, i.e. it is strengthened like in Fig. 13d. Equivalently, it means that if 'late' SST climatology is prescribed in the Arctic or Atlantic, the response is weaker with anomalies forming a similar pattern as the one in 'late' SST conditions (Fig. 13b, c). The total SST (i.e. El Niño anomaly + climatology) in the later period is less than that of the early period, because the climatology in the tropical Pacific has weakened (Fig. 1a) in the late period. However, in this instance, it turns out the change in SST climatology in the Pacific is not a factor. 
(a) MSLP (El Niño + 'high' sea-ice + 'early' SST clim )

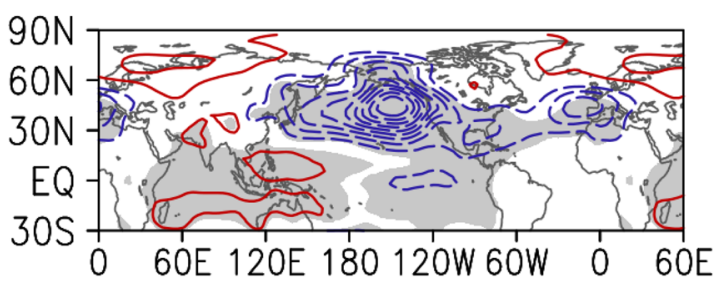

(c) MSLP (El Niño + 'high' sea-ice + 'late' SST clim)

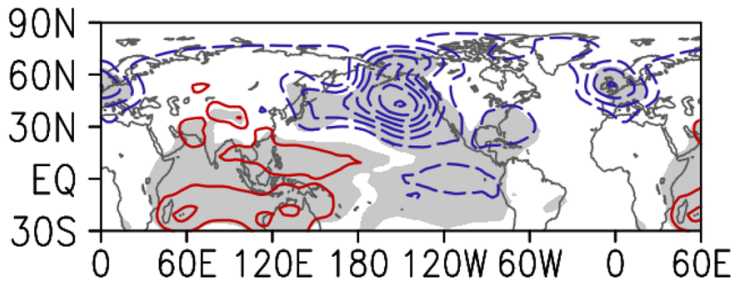

(e) GH200 (El Niño + 'high' sea-ice + 'early' SST clim)

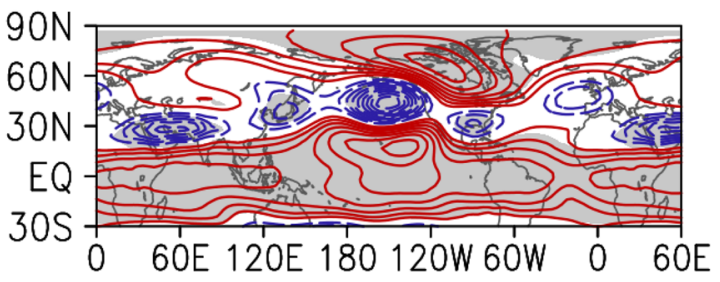

(g) GH200 (El Niño + 'high' sea-ice + 'late' SST clim)

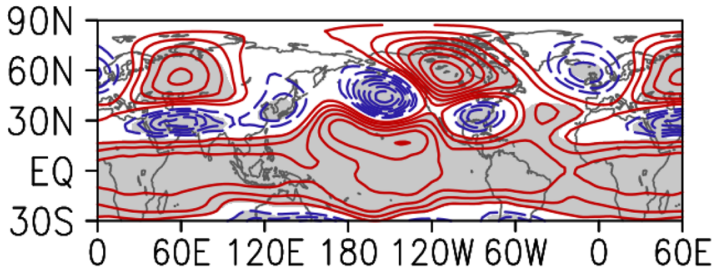

Fig. 13 ICTP AGCM simulated MSLP response to El Niño in conditions with: a 'high' sea-ice and 'early' SST climatology, b 'low' sea-ice and 'late' SST climatology, c 'high' sea-ice and 'late' SST climatology and d 'low' sea-ice and 'early' SST climatology. Panels

Therefore, the model results together indicate the Atlantic and Arctic SST change in recent decades is able to separately weaken the ENSO teleconnection in the NAE area. The later warming of the North Atlantic is related to the Atlantic Multidecadal Oscillation, both in pattern and timing. We suggest that SST in the Atlantic affects the background winds which determine the Rossby wave propagation and interaction with mean flow that are so important for ENSO teleconnection in the NAE (e.g. Hoskins and Karoly 1981; Hoskins and Ambrizzi 1993). A simple inspection of the model experiments performed here indicates a common (b) MSLP (El Niño + 'low' sea-ice + 'late' SST clim)

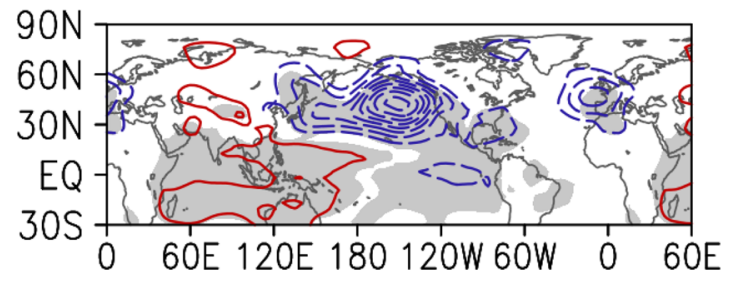

(d) MSLP (El Niño + 'low' sea-ice + 'early' SST clim)

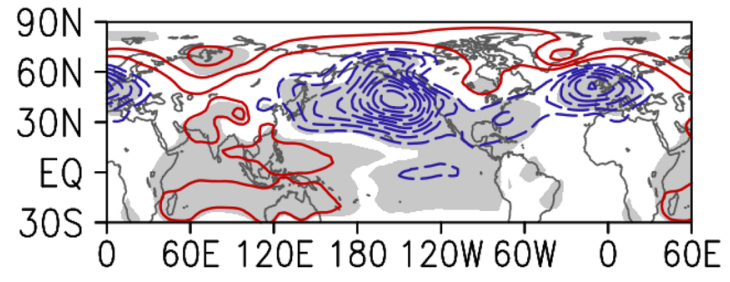

(f) GH200 (El Niño + 'low' sea-ice + 'late' SST clim)

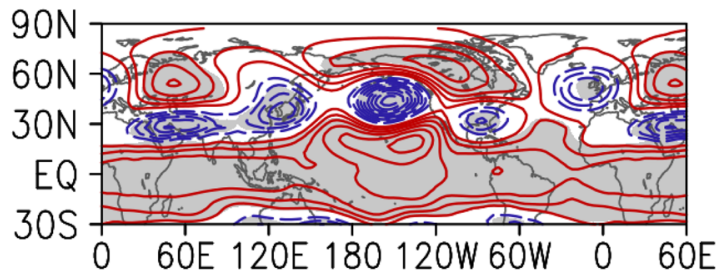

(h) GH200 (El Niño + 'low' sea-ice + 'early' SST clim)

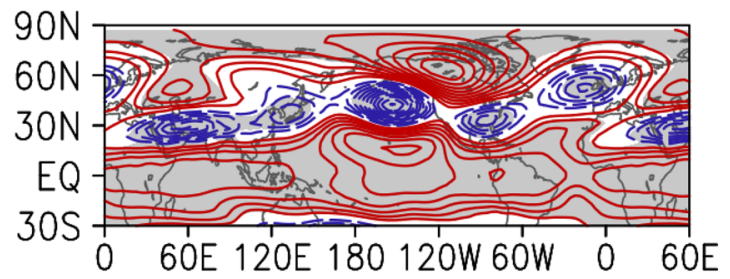

e-h: same as panels $\mathbf{a}-\mathbf{g}$ but for $\mathrm{GH} 200$ response. Shading indicates statistically significant values. Contouring interval is $0.5 \mathrm{hPa}$ in a-d and $5 \mathrm{~m}$ in $\mathbf{e}-\mathbf{h}$. Statistically significant results $(\mathrm{p}<5 \%)$ are shaded

feature is the weaker subtropical jet in the North Atlantic in the earlier period compared to the later one. Consistent with the modulation of the El Niño teleconnections presented above, this only occurs for experiments with Atlantic and Arctic SST changes prescribed (Supp. Fig. S3 shows three examples). This result presented in Supp. Fig. S3 is in agreement with Fig. 11, suggesting that the subtropical jet in the North Atlantic is stronger for periods with weaker teleconnections. Investigation of the changes in complex tropospheric and stratospheric pathways (Jiménez-Esteve and Domeisen 2018; King et al. 2018; Mezzina et al. 2019; 
(a) 'Low'-sea-ice + 'early' SST clim in Indo-Pacific

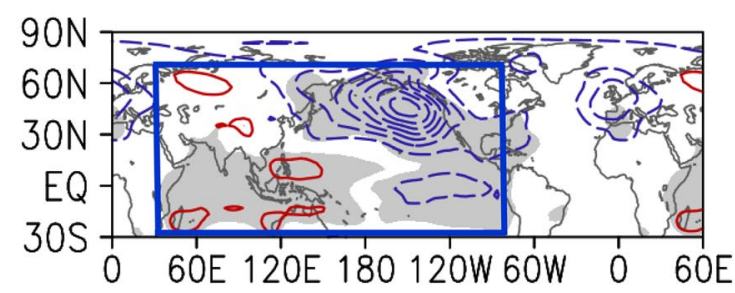

(c) ‘Low'-sea-ice + 'early' SST clim in Atlantic Ocean

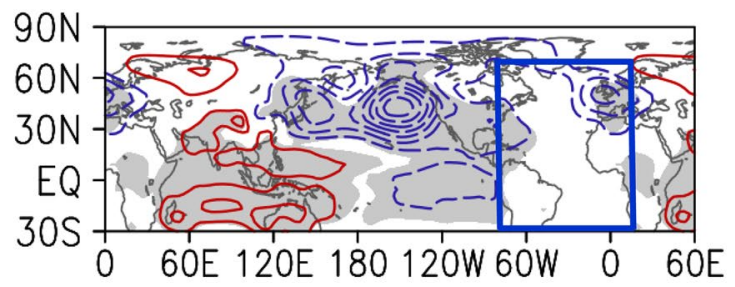

(e) 'Low'sea-ice + 'early' SST clim outside Atlantic Ocean

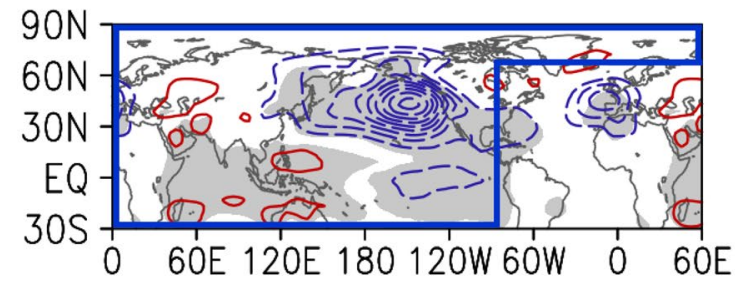

Fig. 14 ICTP AGCM simulated MSLP response to El Niño in conditions with 'low' sea-ice and 'early' (1979-1999) SST climatology prescribed in: a Indian and Pacific Ocean, b Arctic Ocean, c Atlantic Ocean, d Atlantic, Indian and Pacific Ocean, e Arctic, Indian and

Domeisen et al. 2019; Li et al. 2020), and how well models and reanalyses agree with each other, is beyond the scope of the present study.

For completeness, we have conducted additional experiments with El Niño SST anomalies placed in the central Pacific (El Niño Modoki SST pattern, Supp. Fig. S4), as well as the cold phases of both the canonical and central-Pacific ENSO (not shown). In terms of the effect on the strength of atmospheric teleconnections in the NAE area, the results obtained are similar to those for the canonical El Niño as given in Figs. 1 and 13. Note that it is not our aim here to argue that the ENSO teleconnection in NAE is not dependent on ENSO diversity or that there is no non-linearity between the El Niño and La Niña anomalies, but only to report the outcome from the additional experiments.

We believe that our conclusion here regarding the role of Arctic and Atlantic oceans in weakening the ENSO teleconnection in NAE is robust (although it might still be model (b) 'Low'-sea-ice + 'early' SST clim in Arctic Ocean

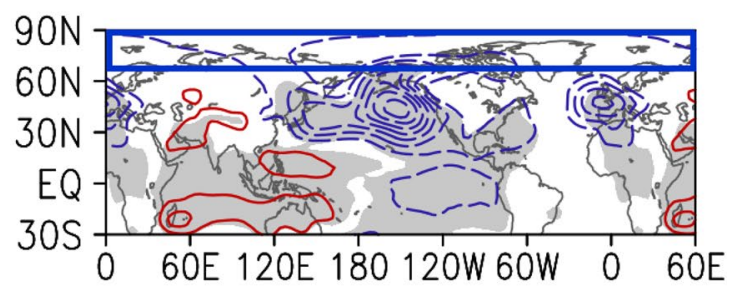

(d) ‘Low'-sea-ice + 'early' SST clim outside Arctic Ocean

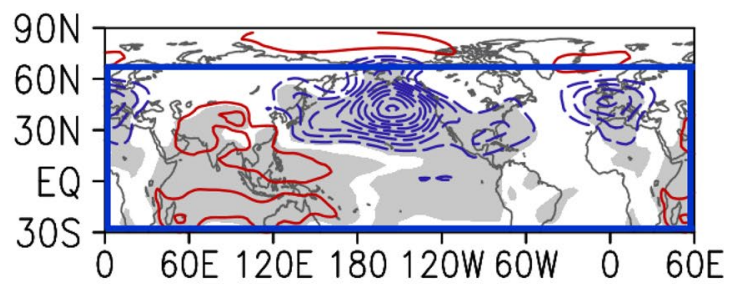

(f) 'Low'-sea-ice + 'early' SST clim in Arctic and Atlantic

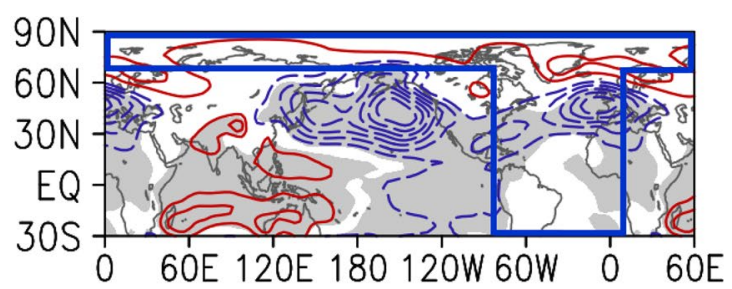

Pacific Ocean and $\mathbf{f}$ Arctic and Atlantic Ocean. Blue rectangles illustrate regions with prescribed 'early' SST climatology; outside those regions the 'late' SST climatology is prescribed. Statistically significant results $(\mathrm{p}<5 \%)$ are shaded. Contouring interval is $0.5 \mathrm{hPa}$

dependent) due to the consistency of the results across a large number of sensitivity experiments performed.

\section{Discussion and conclusions}

The results of our study provide evidence of variability in the atmospheric response to ENSO. Using different approaches (probability distribution of the NAO phases during a particular ENSO phase, running correlation, regression maps) and for different datasets (HadSLP and NOAA 20th Century reanalysis), we demonstrate a weakening in the recent ENSO-NAE teleconnection during late winter. Additional composite analysis agrees with the spatial pattern and the observed changes of the HadSLP regressions on the HadISST Niño 3.4 index presented. Also, the investigation of HadSLP composites for El Niño and La Niña suggests that the observed weakening of the ENSO-NAE teleconnection is mostly tied to the weakening of the El Niño-NAOneg connection. This decrease of the SLP response is visible in the 
composites for La Niña as well. However, because of the generally weaker response to La Niña in the NAE area in the considered period, the observed weakening of the ENSONAE teleconnection can be primarily ascribed to the El Niño phase. The ENSO response in the NAE area has turned from El Niño and negative NAO-like connection to statistically non-significant values. Weakening of the signal is found at the surface (SLP), and also at higher levels (for different variables, e.g. geopotential height, temperature, zonal wind). The correlation between Niño 3.4 and NAO index, as well as regression maps, indicate that the change began to develop in the 1970s.

It is well-known that natural variability is an important source of uncertainty in the ENSO-NAE teleconnection. As highlighted in van Oldenborgh and Burgers (2005), the relatively short period of observations, weak ENSO signal and large atmospheric noise in the extratropics are all limiting factors for investigating the strength and long-term variations of ENSO teleconnections. The modulations of ENSO teleconnections can be small compared to the effects of atmospheric internal variability and it is often challenging to demonstrate high statistical confidence (Sterl et al. 2007; van Oldenborgh et al. 2000). However, the presented analysis of the ENSO-NAE teleconnection, together with the consistent results of targeted model experiments, supports our hypothesis that sea-ice concentration and SST climatology are important factors in the modulation of the ENSO-NAE teleconnection. Recent studies (e.g. Fereday et al. 2020; Michel et al. 2020) using large ensembles of model experiments also reported recent and projected future changes of ENSO teleconnections, further suggesting that modulations of ENSO teleconnections to the Northern Hemisphere could be real in principle and are not just due to statistical artefacts.

Analysis of observed data and reanalysis has pointed to non-stationary behaviour of the ENSO-NAO relationship, with a change in sign of spatial patterns and frequency of co-occurrence of ENSO and NAO phases around 1970s. Moreover, analysis of the ENSO and NAO connection using different definitions of the NAO index (PC-based and station-based) and various approaches to remove the NAO decadal variability (filtering and calculating the index based on 30-year climatologies; not shown) shows good agreement with the results presented in Fig. 3, implying that the observed change cannot be entirely attributed to the recent positive NAO trend. To offer a possible reason behind the described change, we have further investigated the potential role of sea-ice and SST climatology in modulating the ENSO-NAE teleconnection. For that purpose, ICTP AGCM (SPEEDY) has been forced with El Niño SSTs in the tropical Pacific. Sensitivity experiments with different combinations of sea-ice and SST climatology of 'low' (or 'high') sea-ice concentration and 'early' (or 'late') SST conditions enabled the investigation of their roles. Our results indicate that both the sea-ice and SST climatology modulate the ENSO teleconnection over the NAE region. However, their contributions have opposite effects: the Arctic sea-ice loss tends to strengthen the teleconnection, with anomalies resembling a NAO pattern; while it is weakened under the more recent SST climatology. According to the targeted simulations, recent change in the SST climatology in the Atlantic and Arctic is of great importance for the weakening of the ENSO-NAE teleconnection.

Although the focus of our study was to provide an explanation of the observed change in the late winter ENSO-NAE teleconnection by looking at the impact of sea-ice and SST climatology, these two factors are not the only possible influences on ENSO teleconnection to the NAE region. For example, taking into consideration the delayed ENSO influence on the NAE region via the stratosphere (e.g. Herceg-Bulić et al. 2017) and the difference between the late fall, early and late winter atmospheric response to ENSO (Abid et al. 2020b; Ayarzagüena et al. 2018; King et al. 2018) could provide the base for future studies of the ENSO-NAE teleconnection.

Supplementary Information The online version contains supplementary material available at https://doi.org/10.1007/s00382-021-05783-z.

Acknowledgements We thank Z. Pasarić for discussion. This work has been fully supported by Croatian Science Foundation under the project UIP-2017-05-6396 (CroClimGoGreen) and Research Council Norway (project nos. 255027, 275268).

Author contributions Material preparation, data collection and analysis were performed by SI, IHB and MPK. The first draft of the manuscript was written by IHB. Numerical simulations with ICTP AGCM were performed by MPK. All authors contributed to study design, discussion and interpretation of results, writing and editing the manuscript. All authors read and approved the final manuscript.

Funding This research has been fully supported by Croatian Science Foundation under the project UIP-2017-05-6396 (CroClimGoGreen). MPK was supported by Research Council Norway (project nos. 255027, 275268).

Data availability statement The full dataset of ICTP AGCM (SPEEDY) experiments performed in this study is publicly available: https://doi.org/10.11582/2021.00003. Observation datasets obtained from different sources are used in this study. To analyse mean sea level pressure (MSLP) we have used the Hadley Centre (HadSLP2) dataset from: https://www.metoffice.gov.uk/hadobs/hadslp2/. The Niño 3.4 index based on HadISST data used in this study has been retrieved from: https://www.esrl.noaa.gov/psd/gcos_wgsp/Timeseries/Data/ nino34.long.anom.data. NAO index data is provided by the National Center for Atmospheric Research Staff (Eds). Last modified 14 Aug 2020. "The Climate Data Guide: Hurrell North Atlantic Oscillation (NAO) Index (PC-based)." Retrieved from https://climatedataguide. ucar.edu/climate-data/hurrell-north-atlantic-oscillation-nao-index-pcbased. We also performed analysis for several other parameters (MSLP, zonal wind, geopotential height, temperature) taken from the NOAA Twentieth Century Reanalysis V3 1836-2015, provided by NOAA/ OAR/ESRL PSD, Boulder, Colorado, USA https://www.esrl.noaa.gov/ $\mathrm{psd} /$. 
Code availability The data in this study was analysed and presented using Grid Analysis and Display System (GrADS), MATLAB and Python. ICTP AGCM (SPEEDY) is available at: https://www.ictp.it/ research/esp/models/speedy.aspx.

\section{Declaration}

Conflict of interest The authors have no competing interests to declare that are relevant to the content of this article.

Open Access This article is licensed under a Creative Commons Attribution 4.0 International License, which permits use, sharing, adaptation, distribution and reproduction in any medium or format, as long as you give appropriate credit to the original author(s) and the source, provide a link to the Creative Commons licence, and indicate if changes were made. The images or other third party material in this article are included in the article's Creative Commons licence, unless indicated otherwise in a credit line to the material. If material is not included in the article's Creative Commons licence and your intended use is not permitted by statutory regulation or exceeds the permitted use, you will need to obtain permission directly from the copyright holder. To view a copy of this licence, visit http://creativecommons.org/licenses/by/4.0/.

\section{References}

Abid MA, Ashfaq M, Kucharski F et al (2020a) Tropical Indian Ocean mediates ENSO influence over central Southwest Asia during the Wet Season. Geophys Res Lett. https://doi.org/10.1029/2020G L089308

Abid MA, Kucharski F, Molteni F et al (2020b) Separating the Indian and Pacific Ocean impacts on the Euro-Atlantic response to ENSO and its transition from early to late winter. J Clim. https://doi.org/ 10.1175/jcli-d-20-0075.1

Allan R, Ansell T (2006) A new globally complete monthly historical gridded mean sea level pressure dataset (HadSLP2): 1850-2004. J Clim 19:5816-5842. https://doi.org/10.1175/JCLI3937.1

Ayarzagüena B, Ineson S, Dunstone NJ et al (2018) Intraseasonal effects of El Niño-Southern Oscillation on North Atlantic climate. J Clim 31:8861-8873. https://doi.org/10.1175/JCLI-D-18-0097.1

Barnett TP, Latif M, Kirk E, Roeckner E (1991) On ENSO physics. J Clim 4:487-515. https://doi.org/10.1175/1520-0442(1991)004\% 3c0487:oep\%3e2.0.co;2

Bartholy J, Pongrácz R (2006) Regional effects of ENSO in Central/ Eastern Europe. Adv Geosci 6:133-137

Bell CJ, Gray LJ, Charlton-Perez AJ et al (2009) Stratospheric communication of El Niño teleconnections to European winter. J Clim 22:4083-4096. https://doi.org/10.1175/2009JCLI2717.1

Bourke W (1974) A multi-level spectral model. I. Formulation and hemispheric integrations. Mon Weather Rev. https://doi.org/10. 1175/1520-0493(1974)102\%3c0687:amlsmi\%3e2.0.co;2

Branstator G (2002) Circumglobal teleconnections, the jet stream waveguide, and the North Atlantic Oscillation. J Clim 15:18931910. https://doi.org/10.1175/1520-0442(2002)015\%3c1893: CTTJSW\%3e2.0.CO;2

Brönnimann S (2007) Impact of El Niño-Southern oscillation on European climate. Rev Geophys. https://doi.org/10.1029/2006RG0001 99

Bulić IH, Kucharski F (2012) Delayed ENSO impact on spring precipitation over North/Atlantic European region. Clim Dyn 38:25932612. https://doi.org/10.1007/s00382-011-1151-9
Bulić IH, Branković Č, Kucharski F (2012) Winter ENSO teleconnections in a warmer climate. Clim Dyn 38:1593-1613. https://doi. org/10.1007/s00382-010-0987-8

Calvo N, Iza M, Hurwitz MM et al (2017) Northern hemisphere stratospheric pathway of different El Niño flavors in stratosphereresolving CMIP5 models. J Clim 30:4351-4371. https://doi.org/ 10.1175/JCLI-D-16-0132.1

Cattiaux J, Peings Y, Saint-Martin D et al (2016) Sinuosity of midlatitude atmospheric flow in a warming world. Geophys Res Lett. https://doi.org/10.1002/2016GL070309

Cohen J, Screen JA, Furtado JC et al (2014) Recent Arctic amplification and extreme mid-latitude weather. Nat Geosci 7:627-637. https://doi.org/10.1038/ngeo2234

Colfescu I, Schneider EK (2017) Internal atmospheric noise characteristics in twentieth century coupled atmosphere-ocean model simulations. Clim Dyn 49:2205-2217. https://doi.org/10.1007/ s00382-016-3440-9

Czaja A, Frankignoul C, Minobe S, Vannière B (2019) Simulating the midlatitude atmospheric circulation: What might we gain from high-resolution modeling of air-sea interactions? Curr Clim Chang Reports. https://doi.org/10.1007/s40641-019-00148-5

Deser C, Simpson IR, McKinnon KA, Phillips AS (2017) The Northern Hemisphere extratropical atmospheric circulation response to ENSO: How well do we know it and how do we evaluate models accordingly? J Clim 30:5059-5082. https://doi.org/10.1175/ JCLI-D-16-0844.1

Domeisen DIV, Butler AH, Fröhlich K et al (2015) Seasonal predictability over Europe arising from El Niño and stratospheric variability in the MPI-ESM seasonal prediction system. J Clim 28:256-271. https://doi.org/10.1175/JCLI-D-14-00207.1

Domeisen DIV, Badin G, Koszalka IM (2018) How predictable are the Arctic and North Atlantic Oscillations? Exploring the variability and predictability of the Northern Hemisphere. J Clim 31:9971014. https://doi.org/10.1175/JCLI-D-17-0226.1

Domeisen DIV, Garfinkel CI, Butler AH (2019) The teleconnection of El Niño Southern oscillation to the stratosphere. Rev Geophys 57:5-47

Fereday DR, Chadwick R, Knight JR, Scaife AA (2020) Tropical rainfall linked to stronger future ENSO-NAO teleconnection in CMIP5 models. Geophys Res Lett. https://doi.org/10.1029/2020G L088664

Francis JA, Vavrus SJ (2015) Evidence for a wavier jet stream in response to rapid Arctic warming. Environ Res Lett 10:14005. https://doi.org/10.1088/1748-9326/10/1/014005

Gastineau G, Frankignoul C (2015) Influence of the North Atlantic SST variability on the atmospheric circulation during the twentieth century. J Clim. https://doi.org/10.1175/JCLI-D-14-00424.1

Halpert MS, Ropelewski CF (1992) Surface temperature patterns associated with the southern oscillation. J Clim 5:577-593. https://doi. org/10.1175/1520-0442(1992)005\%3c0577:stpawt\%3e2.0.co;2

Hardiman SC, Dunstone NJ, Scaife AA et al (2019) The impact of strong El Niño and La Niña events on the North Atlantic. Geophys Res Lett 46:2874-2883. https://doi.org/10.1029/2018GL081776

Herceg Bulić I, Branković Ć (2007) ENSO forcing of the Northern Hemisphere climate in a large ensemble of model simulations based on a very long SST record. Clim Dyn 28:231-254. https:// doi.org/10.1007/s00382-006-0181-1

Herceg-Bulić I, Mezzina B, Kucharski F et al (2017) Wintertime ENSO influence on late spring European climate: the stratospheric response and the role of North Atlantic SST. Int J Climatol 37:87108. https://doi.org/10.1002/joc. 4980

Horel JD, Wallace JM (1981) Planetary-scale atmospheric phenomena associated with the Southern Oscillation. Mon Weather Rev 109:813-829. https://doi.org/10.1175/1520-0493(1981)109\% 3c0813:PSAPAW\%3e2.0.CO;2 
Hoskins BJ, Ambrizzi T (1993) Rossby wave propagation on a realistic longitudinally varying flow. J Atmos Sci 50:1661-1671. https:// doi.org/10.1175/1520-0469(1993)050\%3c1661:RWPOAR\%3e2.0. $\mathrm{CO} ; 2$

Hoskins BJ, Karoly DJ (1981) The steady linear response of a spherical atmosphere to thermal and orographic forcing. J Atmos Sci 38:1179-1196. https://doi.org/10.1175/1520-0469(1981)038\% 3c1179:TSLROA\%3e2.0.CO;2

Hurrell JW, Kushnir Y, Ottersen G, Visbeck M (2003) An overview of the North Atlantic Oscillation. Geophys Monogr Ser 134:1-35. https://doi.org/10.1029/134GM01

Ineson S, Scaife AA (2009) The role of the stratosphere in the European climate response to El Niño. Nat Geosci 2:32-36. https:// doi.org/10.1038/ngeo381

Iza M, Calvo N (2015) Role of Stratospheric Sudden Warmings on the response to Central Pacific El Niño. Geophys Res Lett 42:24822489. https://doi.org/10.1002/2014GL062935

Jiménez-Esteve B, DI Domeisen V (2018) The tropospheric pathway of the ENSO-North Atlantic teleconnection. J Clim 31:4563-4584. https://doi.org/10.1175/JCLI-D-17-0716.1

Kiladis GN, Diaz HF (1989) Global climatic anomalies associated with extremes in the southern Oscillation. J Clim 2:1069-1090. https://doi.org/10.1175/1520-0442(1989)002\%3c1069:gcaawe\% 3e2.0.co; 2

King MP, Kucharski F, Molteni F (2010) The roles of external forcings and internal variabilities in the Northern Hemisphere atmospheric circulation change from the 1960s to the 1990s. J Clim 23:62006220. https://doi.org/10.1175/2010JCLI3239.1

King MP, Herceg-Bulić I, Bladé I et al (2018) Importance of late fall ENSO teleconnection in the Euro-Atlantic sector. Bull Am Meteorol Soc 99:1337-1343. https://doi.org/10.1175/ BAMS-D-17-0020.1

Kingtse CM, Livezey RE (1986) Tropical-extratropical geopotential height teleconnections during the Northern Hemisphere winter. Mon Weather Rev 114:2488-2515. https://doi.org/10.1175/ 1520-0493(1986)114\%3c2488:teghtd\%3e2.0.co;2

Kucharski F, Molteni F, Bracco A (2006a) Decadal interactions between the western tropical Pacific and the North Atlantic Oscillation. Clim Dyn 26:79-91. https://doi.org/10.1007/ s00382-005-0085-5

Kucharski F, Molteni F, Yoo JH (2006b) SST forcing of decadal Indian Monsoon rainfall variability. Geophys Res Lett. https:// doi.org/10.1029/2005GL025371

Kucharski F, Bracco A, Yoo JH, Molteni F (2007) Low-frequency variability of the Indian monsoon-ENSO relationship and the tropical Atlantic: The "weakening" of the 1980s and 1990s. J Clim 20:4255-4266. https://doi.org/10.1175/JCLI4254.1

Kucharski F, Molteni F, King MP et al (2013) On the need of intermediate complexity general circulation models: a "sPEEDY" example. Bull Am Meteorol Soc 94:25-30. https://doi.org/10. 1175/BAMS-D-11-00238.1

Larkin NK (2005) On the definition of El Niño and associated seasonal average U.S. weather anomalies. Geophys Res Lett 32:L13705. https://doi.org/10.1029/2005GL022738

Lau NC (1981) A diagnostic study of recurrent meteorological anomalies in a $15 \mathrm{yr}$ simulation with a GFDL general circulation model. Mon Weather Rev 109:2287-2311. https://doi.org/ 10.1175/1520-0493(1981)109\%3c2287:ADSORM\%3e2.0.CO;2

Li Y, Lau NC (2012) Impact of ENSO on the atmospheric variability over the North Atlantic in late Winter-Role of transient eddies. J Clim 25:320-342. https://doi.org/10.1175/JCLI-D-11-00037.1

Li RKK, Woollings T, O'Reilly C, Scaife AA (2020) Effect of the North Pacific tropospheric waveguide on the fidelity of model El Niño teleconnections. J Clim 33:5223-5237. https://doi.org/ 10.1175/jcli-d-19-0156.1
Limpasuvan V, Hartmann DL (1999) Eddies and the annular modes of climate variability. Geophys Res Lett 26:3133-3136. https:// doi.org/10.1029/1999GL010478

Lin J, Qian T (2019) A new picture of the global impacts of El Nino-Southern Oscillation. Sci Rep. https://doi.org/10.1038/ s41598-019-54090-5

Lorenzo MN, Taboada JJ, Iglesias I, Gómez-Gesteira M (2011) Predictability of the spring rainfall in Northwestern Iberian Peninsula from sea surfaces temperature of ENSO areas. Clim Change 107:329-341. https://doi.org/10.1007/s10584-010-9991-6

Mezzina B, García-Serrano J, Bladé I, Kucharski F (2019) Dynamics of the ENSO teleconnection and NAO variability in the North Atlantic-European late winter. J Clim. https://doi.org/10.1175/ jcli-d-19-0192.1

Michel C, Li C, Simpson IR et al (2020) The change in the ENSO teleconnection under a low global warming scenario and the uncertainty due to internal variability. J Clim 33:4871-4889. https://doi.org/10.1175/JCLI-D-19-0730.1

Molteni F (2003) Atmospheric simulations using a GCM with simplified physical parametrizations. I: model climatology and variability in multi-decadal experiments. Clim Dyn 20:175-191. https://doi.org/10.1007/s00382-002-0268-2

Molteni F, King MP, Kucharski F, Straus DM (2011) Planetary-scale variability in the northern winter and the impact of land-sea thermal contrast. Clim Dyn 37:151-170. https://doi.org/10. 1007/s00382-010-0906-z

Molteni F, Stockdale TN, Vitart F (2015) Understanding and modelling extra-tropical teleconnections with the Indo-Pacific region during the northern winter. Clim Dyn 45:3119-3140. https:// doi.org/10.1007/s00382-015-2528-y

Molteni F, Roberts CD, Senan R et al (2020) Boreal-winter teleconnections with tropical Indo-Pacific rainfall in HighResMIP historical simulations from the PRIMAVERA project. Clim Dyn 55:18431873. https://doi.org/10.1007/s00382-020-05358-4

Moron V, Ward MN (1998) ENSO teleconnections with climate variability in the european and african sectors. Weather 53:287-295. https://doi.org/10.1002/j.1477-8696.1998.tb06403.x

Poli P, Hersbach H, Dee DP et al (2016) ERA-20C: an atmospheric reanalysis of the twentieth century. J Clim 29:4083-4097. https:// doi.org/10.1175/JCLI-D-15-0556.1

Power S, Casey T, Folland C et al (1999) Inter-decadal modulation of the impact of ENSO on Australia. Clim Dyn 15:319-324. https:// doi.org/10.1007/s003820050284

Rayner NA, Parker DE, Horton EB et al (2003) Global analyses of sea surface temperature, sea ice, and night marine air temperature since the late nineteenth century. J Geophys Res Atmos. https:// doi.org/10.1029/2002jd002670

Ren HL, Scaife AA, Dunstone N et al (2019) Seasonal predictability of winter ENSO types in operational dynamical model predictions. Clim Dyn 52:3869-3890. https://doi.org/10.1007/ s00382-018-4366-1

Rodó X, Baert E, Comin FA (1997) Variations in seasonal rainfall in Southern Europe during the present century: relationships with the North Atlantic Oscillation and the El Niño-Southern Oscillation. Clim Dyn 13:275-284. https://doi.org/10.1007/s003820050 165

Rodríguez-Fonseca B, Suárez-Moreno R, Ayarzagüena B et al (2016) A review of ENSO influence on the North Atlantic. A non-stationary signal. Atmosphere (Basel) 7:1-19. https://doi.org/10.3390/atmos 7070087

Ropelewski CF, Halpert MS (1986) North American precipitation and temperature patterns associated with the El Nino/Southern Oscillation (ENSO). Mon Weather Rev 114:2352-2362. https://doi.org/ 10.1175/1520-0493(1986)114\%3c2352:NAPATP\%3e2.0.CO;2

Ropelewski CF, Halpert MS (1989) Precipitation patterns associated with the high index phase of the Southern Oscillation. J Clim 
2:268-284. https://doi.org/10.1175/1520-0442(1989)002\% 3c0268:ppawth\%3e2.0.co;2

Scaife AA, Arribas A, Blockley E et al (2014) Skillful long-range prediction of European and North American winters. Geophys Res Lett 41:2514-2519. https://doi.org/10.1002/2014GL059637

Scaife AA, Comer RE, Dunstone NJ et al (2017) Tropical rainfall, Rossby waves and regional winter climate predictions. Q J R Meteorol Soc 143:1-11. https://doi.org/10.1002/qj.2910

Screen JA, Deser C, Smith DM et al (2018) Consistency and discrepancy in the atmospheric response to Arctic sea-ice loss across climate models. Nat Geosci 11:155-163. https://doi.org/10.1038/ s41561-018-0059-y

Simpson IR, Blackburn M, Haigh JD (2009) The role of eddies in driving the tropospheric response to stratospheric heating perturbations. J Atmos Sci 66:1347-1365. https://doi.org/10.1175/ 2008JAS2758.1

Slivinski LC, Compo GP, Whitaker JS et al (2019) Towards a more reliable historical reanalysis: improvements for version 3 of the twentieth century Reanalysis system. Q J R Meteorol Soc 145:2876-2908. https://doi.org/10.1002/qj.3598

Smith SR, O'Brien JJ (2001) Regional snowfall distributions associated with ENSO: implications for seasonal forecasting. Bull Am Meteorol Soc 82:1179-1191. https://doi.org/10.1175/1520-0477(2001) 082\%3c1179:RSDAWE\%3e2.3.CO;2

Sterl A, van Oldenborgh GJ, Hazeleger W, Burgers G (2007) On the robustness of ENSO teleconnections. Clim Dyn 29:469-485. https://doi.org/10.1007/s00382-007-0251-z

Toniazzo T, Scaife AA (2006) The influence of ENSO on winter North Atlantic climate. Geophys Res Lett 33:L24704. https://doi.org/10. 1029/2006GL027881

Vallis GK, Gerber EP, Kushner PJ, Cash BA (2004) A mechanism and simple dynamical model of the North Atlantic Oscillation and annular modes. J Atmos Sci. https://doi.org/10.1175/15200469(2004)061\%3c0264:amasdm\%3e2.0.co;2

Van Loon H, Madden RA (1981) The Southern Oscillation. Part I: global associations with pressure and temperature in Northern winter ( India, Pacific Ocean, Rocky Mountains, Atlantic Ocean). Mon Weather Rev 109:1150-1162. https://doi.org/10.1175/15200493(1981)109\%3c1150:TSOPIG\%3e2.0.CO;2

van Oldenborgh GJ, Burgers G (2005) Searching for decadal variations in ENSO precipitation teleconnections. Geophys Res Lett. https:// doi.org/10.1029/2005GL023110 van Oldenborgh GJ, Burgers G, Tank AK (2000) On the El Nino teleconnection to spring precipitation in Europe. Int J Climatol 20:565-574. https://doi.org/10.1002/(SICI)1097-0088(200004) 20:5\%3c565::AID-JOC488\%3e3.0.CO;2-5

van Oldenborgh GJ, Balmaseda MA, Ferranti L et al (2005) Did the ECMWF seasonal forecast model outperform statistical ENSO forecast models over the last 15 years? J Clim 18:3240-3249. https://doi.org/10.1175/JCLI3420.1

Walsh JE, Chapman WL (2001) 20th-century sea-ice variations from observational data. Ann Glaciol. https://doi.org/10.3189/17275 6401781818671

Wang C, Picaut J (2004) Understanding ENSO physics—a review. In: Geophysical Monograph sSeries. American Geophysical Union, Washington, pp 21-48

Warner JL, Screen JA, Scaife AA (2019) Links between Barents-Kara sea ice and the Extratropical Atmospheric Circulation explained by internal variability and tropical forcing. Geophys Res Lett. https://doi.org/10.1029/2019g1085679

Wettstein JJ, Wallace JM (2010) Observed patterns of month-to-month storm-track variability and their relationship to the background flow. J Atmos Sci 67:1420-1437. https://doi.org/10.1175/2009J AS3194.1

Woollings T, Franzke C, Hodson DLR et al (2015) Contrasting interannual and multidecadal NAO variability. Clim Dyn 45:539-556. https://doi.org/10.1007/s00382-014-2237-y

Zhang W, Wang L, Xiang B et al (2015) Impacts of two types of La Niña on the NAO during boreal winter. Clim Dyn. https://doi.org/ 10.1007/s00382-014-2155-z

Zhang W, Wang Z, Stuecker MF et al (2019) Impact of ENSO longitudinal position on teleconnections to the NAO. Clim Dyn 52:257274. https://doi.org/10.1007/s00382-018-4135-1

Publisher's Note Springer Nature remains neutral with regard to jurisdictional claims in published maps and institutional affiliations. 